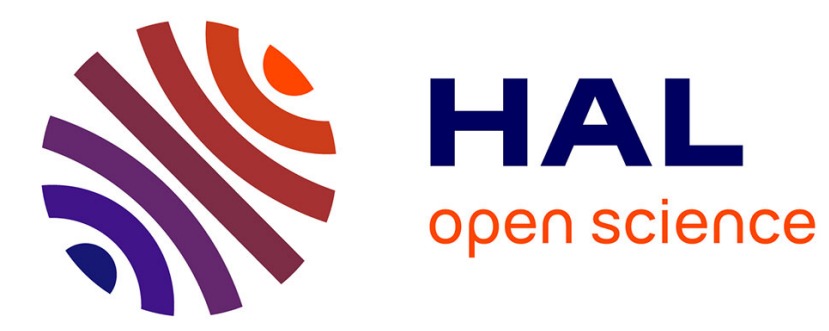

\title{
Characteristics, fate, and impact of marine plastic debris exposed to sunlight: A review
}

\author{
Maria Masry, Stéphanie Rossignol, Jean-Luc Gardette, Sandrine Therias, \\ Pierre-Olivier Bussière, Pascal Wong-Wah-Chung
}

\section{To cite this version:}

Maria Masry, Stéphanie Rossignol, Jean-Luc Gardette, Sandrine Therias, Pierre-Olivier Bussière, et al.. Characteristics, fate, and impact of marine plastic debris exposed to sunlight: A review. Marine Pollution Bulletin, 2021, 171, pp.112701. 10.1016/j.marpolbul.2021.112701 . hal-03301884

\section{HAL Id: hal-03301884 \\ https://hal.uca.fr/hal-03301884}

Submitted on 25 Oct 2021

HAL is a multi-disciplinary open access archive for the deposit and dissemination of scientific research documents, whether they are published or not. The documents may come from teaching and research institutions in France or abroad, or from public or private research centers.
L'archive ouverte pluridisciplinaire HAL, est destinée au dépôt et à la diffusion de documents scientifiques de niveau recherche, publiés ou non, émanant des établissements d'enseignement et de recherche français ou étrangers, des laboratoires publics ou privés. 


\section{Marine Pollution Bulletin \\ Characteristics, fate, and impact of marine plastic debris exposed to sunlight: a review. --Manuscript Draft--}

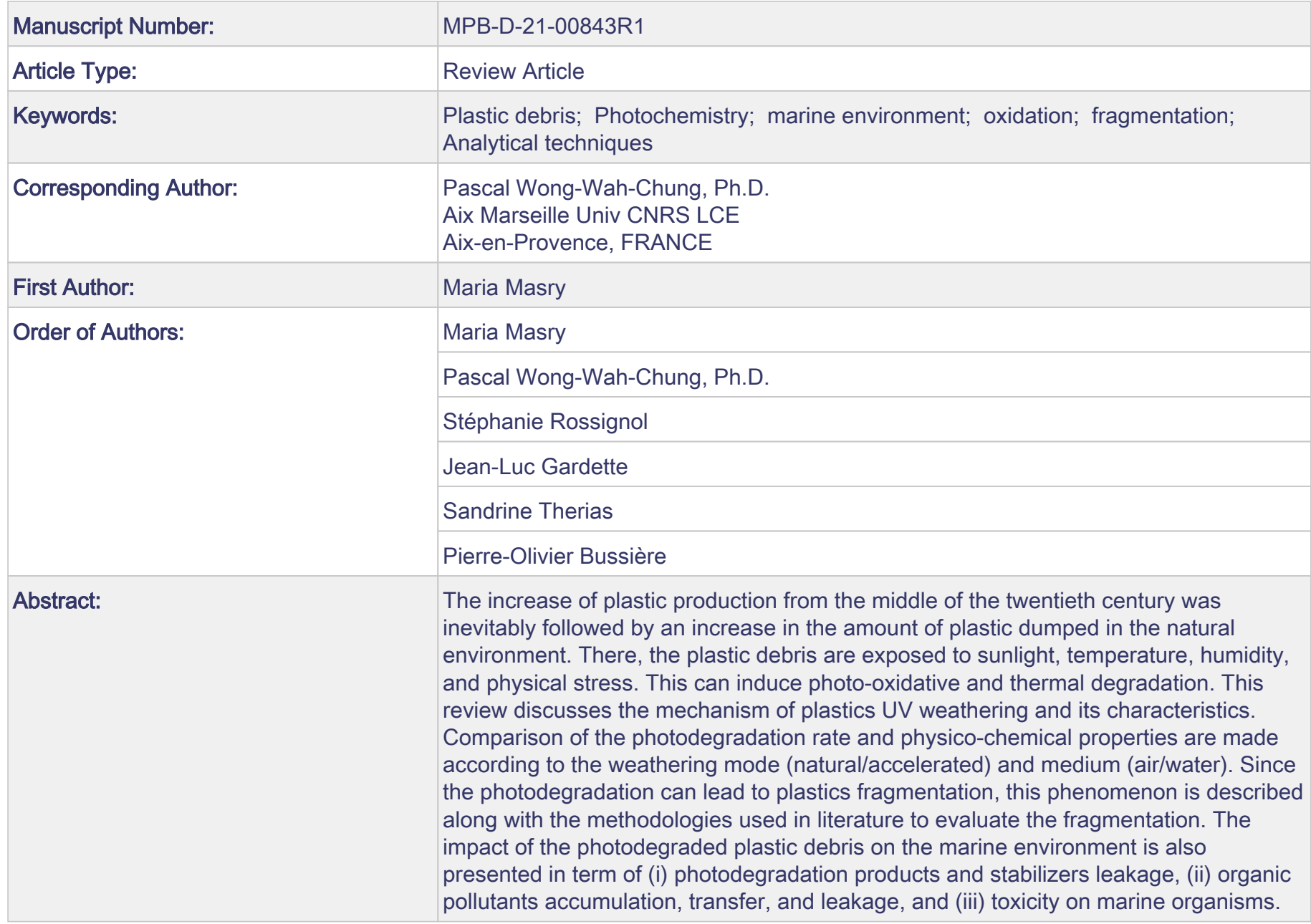




\section{(Aix *Marseille universite}

Pascal WONG-WAH-CHUNG

Professor

Université Aix-Marseille

Laboratoire de Chimie de l'Environnement

Europôle de l'Arbois, Bât. Villemin, BP 80

13545 Aix-en-Provence Cedex 4

Tel : 0033442908402

E-mail : pascal.wong-wah-chung@univ-amu.fr

Dear Editor,

We would like to thank the referees for their positive answer to the publication of our paper and their last comments and suggestions to improve the quality of the paper.

Please find enclosed the final revised paper co-authored with Maria Masry, Stéphanie Rossignol, Jean-Luc Gardette, Sandrine Therias and Pierre-Olivier Bussière entitled: "Characteristics, fate, and impact of marine plastic debris exposed to sunlight: a review" referred MPB-D-21-00843.

With best regards, Yours sincerely.

Pr. P. Wong-Wah-Chung
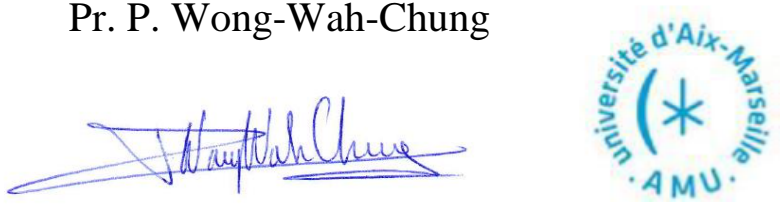


\section{Reviewer \#1:}

This review focused on the mechanism of plastics UV weathering and its characteristics, excluding other factors such as physical stress.

This paper is well documented, well written and well structured.

\section{Major comments}

For the different sections, from a conceptual point of view, authors review the most interesting finding and given some results/findings for a few numbers of polymer. For these different sections, I would suggest to try to generalize on all polymers and/or to conduct some more systematic comparison between polymer (--/-/+/++), when possible.

Thank you for this observation, a table comparing polymers behavior was added to the final manuscript line 296.

Table 1: Qualitative comparison of polymer behavior in term of weathering extent in air / water medium (IR carbonyl and hydroxyl groups bands) (Biber et al., 2019; Cai et al., 2018; Pimentel et al., 2005; Ranjan and Goel, 2019; Tang et al., 2019, 2018), fragmentation (number of generated fragments) (Kalogerakis et al., 2017; Lambert and Wagner, 2016a; Song et al., 2017; Weinstein et al., 2016) and dissolution (mass of plastics and dissolved organic carbon) (Lee et al., 2020; Ward et al., 2019; Zhu et al., 2020). Symbols: ++ resistant, -- fragile and $\mathrm{x}$ not mentioned.

\begin{tabular}{|l|c|c|c|c|}
\hline & Air UV & Water UV & Fragmentation & Dissolution \\
\hline PE & + & ++ & ++ & ++ \\
\hline PP & + & ++ & ++ & + \\
\hline PS & - & -- & -- & - \\
\hline PET & + & ++ & ++ & $\mathrm{x}$ \\
\hline PLA & $\mathrm{x}$ & $\mathrm{x}$ & - & $\mathrm{x}$ \\
\hline PVC & + & ++ & $\mathrm{x}$ & \\
\hline
\end{tabular}

Knowledge is required to balance contribution of the different mechanisms in plastic fragmentation, i.e. UV weathering vs. physical stress. Authors highlight that photooxidation in terrestrial environment is faster compared with other degradation processes (Lambert and Wagner, 2016a; Wang et al., 2016). How to be sur of this very strong hypothesis? New knowledge on the plastic litter dynamic in the landto-sea continuum was recently produced, demonstrating very long residence time of litter in estuary and in bank and this assumption should be examined in light of the recent advances.

Thank you for this comment. Problems in investigation of outdoor photodegradation of various polymers are complex, due to concerted or cyclic attacks of regular as well as casual atmospheric environmental stresses and their combinations on polymers.

"It is generally considered that radiation in the ultraviolet (UV) and visible is the primary factor in outdoor polymer weathering. Effects from heat, moisture, pollutants, mechanical stresses, and biological attack can come into play, but usually the weathering process begins with a photochemical event" (J.E. Pickett, D.A. Gibson, M.M. Gardner, Effects of irradiation conditions on the weathering of engineering thermoplastics. Polymer Degradation and Stability 93 (2008) 1597-1606).

"Polymers exposed outdoors can degrade through the action of several agents, including solar ultraviolet (UV) radiation; water; pollutants (in gaseous form or, more potently, as acid-rain); elevated temperature; and temperature changes. In a majority of cases, the main cause of property deterioration is photooxidation, which is initiated by UV irradiation and, as a consequence, much laboratory photo-ageing testing is conducted to determine the weatherability of polymers and to test 
the effectiveness of stabilisers introduced to improve their weather resistance" (Jim R. White, Polymer ageing: physics, chemistry or engineering? Time to reflect. C. R. Chimie 9 (2006) 1396-1408).

We propose the following modification from lines 87 to 91 :

It is generally considered that radiation in the ultraviolet (UV) and visible is the primary factor in outdoor polymer weathering. Effects from heat, moisture, pollutants, mechanical stresses, and biological attack can come into play, but usually the weathering process begins with a photochemical event (Pickett et al., 2008; White, 2006). Giving the importance of photooxidation for determining the fate and impact of plastic debris, the aim of this work is to give an overview on plastics photodegradation in the marine environment.

In the section 2.2 Chemical modification, authors stated that oxidation leads to some modification of IR spectrum and provide very few examples. I recommended to conduct a systematic approach and to examine for the most common polymers these modifications. In a systematic way. By this way, limited or drastic modification would be better highlighted and a comparison between polymer can be done. As mentioned in the manuscript, the carbonyl band is largely employed to characterize the UV weathering extent of the most common polymers such as polyolefins PVC, PS, PLA, PET and ABS (L. 157 - 159). Labeling the modifications as limited or drastic is not possible as it depends on the exposure time, conditions and possible stabilizers added to the polymer matrix. The term dramatic in the manuscript in the description of infrared analysis was removed (L. 143).

The formation of the oxidation products leads to dramatic modifications of the infrared spectrum of the polymer and infrared spectroscopy has been recognized for a long time as a very useful tool in the identification of marine plastic debris and in the characterization of the chemical modifications provoked by ageing (Jung et al., 2018, 2018; Lobo and Bonilla, 2003; Pavia et al., 2008; Rugg et al., 1954).

In many parts of the manuscript, Authors mentioned "weathering degree" but no definition nor qualitative criteria are given to defined this degree. What mean weathering degree for authors?

Thank you for pointing that out, weathering extent would be better. We have changed degree by extent in the manuscript.

The weathering extent corresponds to the chemical and physical modifications that the plastic undergoes according to its UV exposure time and external weathering conditions. It is not an absolute criteria nor a given value to be determined, but rather a relative criteria allowing the comparison of the aging extent of different plastic samples as it can be defined by one or several parameters according to the study.

This definition was added to the manuscript lines 115 to 119.

As for the criteria, as mentioned in the manuscript, weathering extent can be characterized by chemical modifications and the formation of oxidation products in infrared spectroscopy (L. 140-142 The identification and quantification of the oxidation products are essential for the understanding of the mechanism of degradation and to determine the weathering extent of plastic debris) mainly carbonyl index (L. 157 - 159 the carbonyl band is largely employed to characterize the UV weathering extent of polymers) as well as spectra modifications in Raman spectroscopy (L. 174 - 175 According to the polymer type, photodegradation mechanism and weathering extent changes in the Raman spectra can occur). Even though in some cases, mainly after the plastic is exposed to water, it is hard to determine the weathering extent or exposure time, to our knowledge there is no other qualitative criteria for the determining of the weathering extent. 
L322-323. Eventually, this process induces the splitting of the plastic, thus to the formation of plastics fragments and secondary microplastics. Was the formation of microplastics (or smaller size-particles) by the way of UV oxidation demonstrated or only suggested? This point is of prime importance.

Fragmentation of plastic debris exposed to UV in air is not likely to occur without mechanical forces. On the other hand, fragmentation of plastic debris exposed to UV in water can occur without any external mechanical forces. Thus, the fragmentation due to the formation of cracks do not correlate with the oxidation level (quantity of oxygenated functional groups at the plastics surface). This was demonstrated in two main studies: Song et al. 2017, Julienne et al., 2019 and suggested by others such as Andrady et al., 2017.

Clarification on this point was added to manuscript.

L. 339 - 345 In the case of plastic debris exposed to UV in air, fragmentation is not likely to occur without mechanical forces (Song et al., 2017). For water weathered plastics, cracks can propagate through the plastics, and water probably accelerates the propagation of these cracks. Thus, for plastic debris exposed to UV in water, fragmentation can occur without any external mechanical forces (Julienne et al., 2019). Eventually, this process induces the splitting of the plastic, thus to the formation of plastics fragments and secondary microplastics (Andrady, 2017; Julienne et al., 2019; ter Halle et al., 2016).

In the section, 4.2 dissolution of plastic, a comparison between polymer (at least about their potential to be solubilized) has to be done.

Thank you for this comment, the following was added to the manuscript L. 435 - 437: Overall, the mass of plastics was reduced, and the dissolved organic carbon showed an increase according to UV exposure time. EPS degraded at a faster rate than PP and PE with PE being the most resistant to dissolution.

\section{Minor comments}

Graphical abstract: mechanical stress should be also included.

Mechanical stress was added to the graphical abstract according to this comment.

L64. In 2018 more than 350 million tons of plastic were produced worldwide, China being the biggest plastic producer contributing with $30 \%$ of the world's production. Please update our figure and also included the fiber production.

Thank you for this comment. The numbers were updated according to plastics Europe latest issue and fiber production was added as well L. 64 - 66: In 2019, 368 million tons of plastic and 73.5 million tons of synthetic fibers were produced worldwide, China being the biggest plastic producer contributing with $31 \%$ of the world's production.

L86-88. Authors quoted "Since in the terrestrial environment, photooxidation is faster compared with other degradation processes (Lambert and Wagner, 2016a; Wang et al., 2016), the aim of this work is to give an overview on plastics photodegradation in the marine environment.

This was changed in the manuscript to the following:

L. 90 - 91 Giving the importance of photooxidation for determining the fate and impact of plastic debris, the aim of this work is to give an overview on plastics photodegradation in the marine environment.

136 In many cases, photodegradation mostly occurs at the surface of the polymer. Microsurface is maybe more relevant. What is the thickness of the oxidized surface?

It is a common observation that the chemical degradation in a polymer exposed to high UV irradiation is strong at the surface but falls off steeply in the interior of the sample. This is generally attributed to oxygen starvation in the interior and to a decrease of the absorbed light penetrating into the polymer. The most widespread cause of heterogeneous degradation of polymers results then from oxygen 
diffusion-limited effects and limitation of the penetration of light. Oxygen diffusion-limited effects are likely to be observed in the conditions of accelerated aging, if the rate of oxygen consumption exceeds the rate of oxygen permeation; the oxidation occurs in the surface layers whereas the core remains practically unoxidized.

The importance of these effects depends then on several parameters:

- intrinsic parameters, related to the material geometry (e.g. sample thickness), coupled with the oxygen consumption rate which depends on the reactivity of the polymer, the nature of the additives, the oxygen permeability of the material;

- external parameters that result from the conditions in which the aging is carried out which include both the light intensity and the sample temperature, as well as the oxygen pressure during the weathering.

We propose the following modification: L. 138 - 140 Depending on the polymer and on the weathering conditions (irradiance, temperature, oxygen permeability etc.) the thickness of the degraded layer can be limited to a few tens of microns or even less (Malajati, 2009; Nagai et al., 2003; Pospišil et al., 2006; Rivaton et al., 2005; Sinturel et al., 1999).

L113-121. Appears not so relevant in section 2.1 Visual modification. I understand that in this review, a link between plastic oxidation and microplastic scientific community needs to be woven but no relevant from my point of view

Thank you for this comment, this section was removed from the manuscript.

L199. The surface degradation increases with the UV exposure time. Yes, but very complicated to established link with time in environment.

Thank you for this remark, clarifications were added in the manuscript: L. 201 - 202 In the case where a plastic is exposed to the same external conditions, the surface degradation should increase with the UV exposure time.

L307-310. UV exposure can lead to the oxidation of the plastic surface and its embrittlement, after L308 "mechanical forces caused by wind action, current and tides can induce fragmentation and / or dissolution according to environmental conditions and plastic type". Mechanical forces could also favor the oxidization of the surface.

In this review, the term oxidation is used to describe the formation of oxygen containing groups in the plastic matrix. In literature, according to our knowledge, there is no direct evidence proving that mechanical forces can favor the oxidation of the surface of marine plastic debris. The oxidation is mainly affected by external conditions (temperature, UV exposure, water composition etc.).

In the case of plastic debris, a study by Song et al., 2017 showed that polyolefins were minimally fragmented by mechanical abrasion without photooxidation by UV. Thus, UV exposure combined with temperature and external conditions that causes plastics oxidation and fragilization before mechanical forces induce the fragmentation.

L369. the particle size distribution showed an increase in particle concentration with decreasing particle size. A comparison of these different size distributions could be relevant, to compared the fragmentation of different polymers.

Thank you for this comment, an example of the size distribution was added to the manuscript:

L. 398 - 401 In this study over 73\% of fragments were below $100 \mu \mathrm{m}$ and over $97 \%$ were below $300 \mu \mathrm{m}$. In the case of EPS fragments, around 104 particles/pellet were below $100 \mu \mathrm{m}, 1.5$ particles/pellet were at $200 \mu \mathrm{m}$ and less than a 1 particle/pellet were at $1 \mu \mathrm{m}$. 


\section{Reviewer \#2:}

The manuscript entitled "Characteristics, fate, and impact of marine plastic debris exposed to sunlight: a review" brings an in-depth assessment of the current literature of plastic debris and its degradation and pollution effects. For sure it will be a key-reference for future studies on this subject for scientists, the general people and especially policy makers. In fact, the manuscript covers all the essential issues related to plastic properties an, degradation and its effects on the environment and marine fauna. But, the issue of 'temperature' seems to be underrepresented in its importance.

As a resident and scientist living in a tropical country. i.e., where the average monthly temperature does not fall below $18^{\circ} \mathrm{C}$ throughout the year and near-permanent winds (called trade winds) affect beaches, the degradation of plastic would necessarily follow different paths when compared to temperate and cold weather. I searched the current literature and found very limited information of the processes involving plastic degradation speed when exposed to high temperatures of tropical beaches, that can easily reach and maintain 60 degrees Celsius for several hours (due to silica and quartz). There are opoen questions that should be addressed in a review paper: does intense heat break can cause plastic break (and degradation) more easily and thus make it available more quickly to the marine fauna? Does it explain why marine turtles in tropical areas consume so much plastic?

As such, there could be inserted some graphic representation of the effects of degradation on different environments, from the Arctic to the Equator and then to the Antarctic. In the same way, this section: Lines 248-255 = "Thus, the accelerated weathering presented an acceleration rate ranging overall from 2.5 to 30 times the natural weathering depending on the polymer type, the region and accelerated conditions used. It is worth noting that limits to acceleration may exist above an irradiance threshold due to the fact that recombination and/or disproportionation become predominant compared to realistic propagation (Therias et al., 2021). This was demonstrated for PE samples and we can infer that such threshold can depend on the kind of polymer. In addition, the same authors proved that temperature could be a major parameter affecting the photooxidation degradation rate of nonabsorbing polymers because of its essential role in thermal activation." deserves more detailed information, as it generally touches the variability of plastic degradation by 'region' and its 'temperature'. In my opinion, the paper would greatly increase its visibility if it includes more detailed data on the temperature variability on beaches in different gradients of latitude and its effects of plastic degradation. The perception of plastic debris is different among different regions of the world, and maybe physical degradation differences is connected to this perception.

Thanks for the opportunity to revise this manuscript, for sure it will be a landmark on the theme of plastic degradation.

Dear Reviewer: We thank you for these comments which will help improve our manuscript. There are many fundamental issues in your comments concerning the role of temperature in the photo oxidation process which are of great importance and require a more detailed explanation, as you are suggesting. We thank you for giving us the opportunity to discuss this major point.

May we draw some general comments regarding thermo-oxidation vs. photo-oxidation:

- The (apparent) activation energies measured for the photo oxidation of polyolefins are relatively high. We have measured $74 \mathrm{~kJ} / \mathrm{mol}$ for LDPE in the range $51-65^{\circ} \mathrm{C}$ (Therias 2021). Similar values (activation energies in the range $30-50^{\circ} \mathrm{C}$ around $85 \mathrm{~kJ} / \mathrm{mol}$ for photodegradation of HDPE) were reported by Fairbrother (A. Fairbrother et al. Polymer Degradation and Stability 165 (2019) 153-160 Temperature and light intensity effects on photodegradation of high-density polyethylene). In the case of polypropylene, Audoin had reported $55 \mathrm{~kJ} / \mathrm{mol}$ (L. Audouin et al. Polymer degradation and Stability 
60 (2015) 137-143 Effect of temperature on the photooxidation of polypropylene films). These values are rather important, and the consequences of high temperatures on the rate of degradation of polymers (at least polyolefins) could be underestimated. This means that, as an example, increasing the temperature from 50 to $60^{\circ} \mathrm{C}$ would provoke an acceleration of photo oxidation by a factor 2.3 , and from 40 to $60^{\circ} \mathrm{C}$ by a factor around 5 ! On sunny days, the temperature rises quickly and is within a few degrees of maximum throughout the sunny part of the day. As you point out in your comment, when exposed at temperature around $60^{\circ} \mathrm{C}$ for several hours on tropical beaches, polymers would degrade faster. At the same time the irradiance is usually also very high, and depending on the polymer (non light-absorbing polymers such as polyolefins or absorbing polymers such as PC, PS, PET,...), an increase of irradiance can provoke -or not- a faster photooxidation. The consequence is that a drastic photooxidation is likely to occur within these periods of time.

You are right when you say that intense heat can cause plastic break (and degradation) more easily and thus make it available more quickly to the marine fauna. However, this is very difficult to be quantified since there is no linear relationship between the average mean temperature and fluctuating temperatures. As temperatures are constantly changing in outdoors weathering, a direct comparison between different locations is unpractical. Many data characterizing climatic conditions in 79 locations from 19 countries can be found in the book "Weathering Handbook" published by Jerzy Wypych (ISBN 1-895198-00-3)

Considering your comments, we propose to modify our manuscript by adding the following from line 254:

It is worth noting that limits to acceleration may exist above an irradiance threshold due to the fact that recombination and/or disproportionation become predominant compared to realistic propagation (Therias et al., 2021). This was demonstrated for PE samples and we can infer that such threshold depends on the polymer type. In addition, the same authors showed that temperature affects the photooxidative degradation rate of PE with a measured apparent activation of $74 \mathrm{~kJ} / \mathrm{mol}$ (Therias et al., 2021). In the case of $P P$, an activation energy for photooxidation around $55 \mathrm{~kJ} / \mathrm{mol}$ had been determined (Audouin et al., 1998). The consequence is that, with an activation energy of $74 \mathrm{~kJ} / \mathrm{mol}$, an increase of temperature from 50 to $60^{\circ} \mathrm{C}$ would double the rate of photooxidation, and the rate would be multiplied by a factor 5 when passing from 40 to $60^{\circ} \mathrm{C}$. Thus, the variability of temperature by region is an important parameter that should be considered, but difficult to be predicted. The rate of photooxidation of a given polymer is then expected to present strong variations depending on the location, the season, and the hour, with very important oxidation rates with higher temperatures. In other applications where temperature plays an important role on the photodegradation, i.e. solar mirrors industry, empirical models have been established to take into account how the variations of temperature and the reached maximum temperature impact the degradation (Avenel et al., 2018; Escobar and Meeker, 2006). 
Photodegradation and fragmentation due to sunlight and mechanical stress

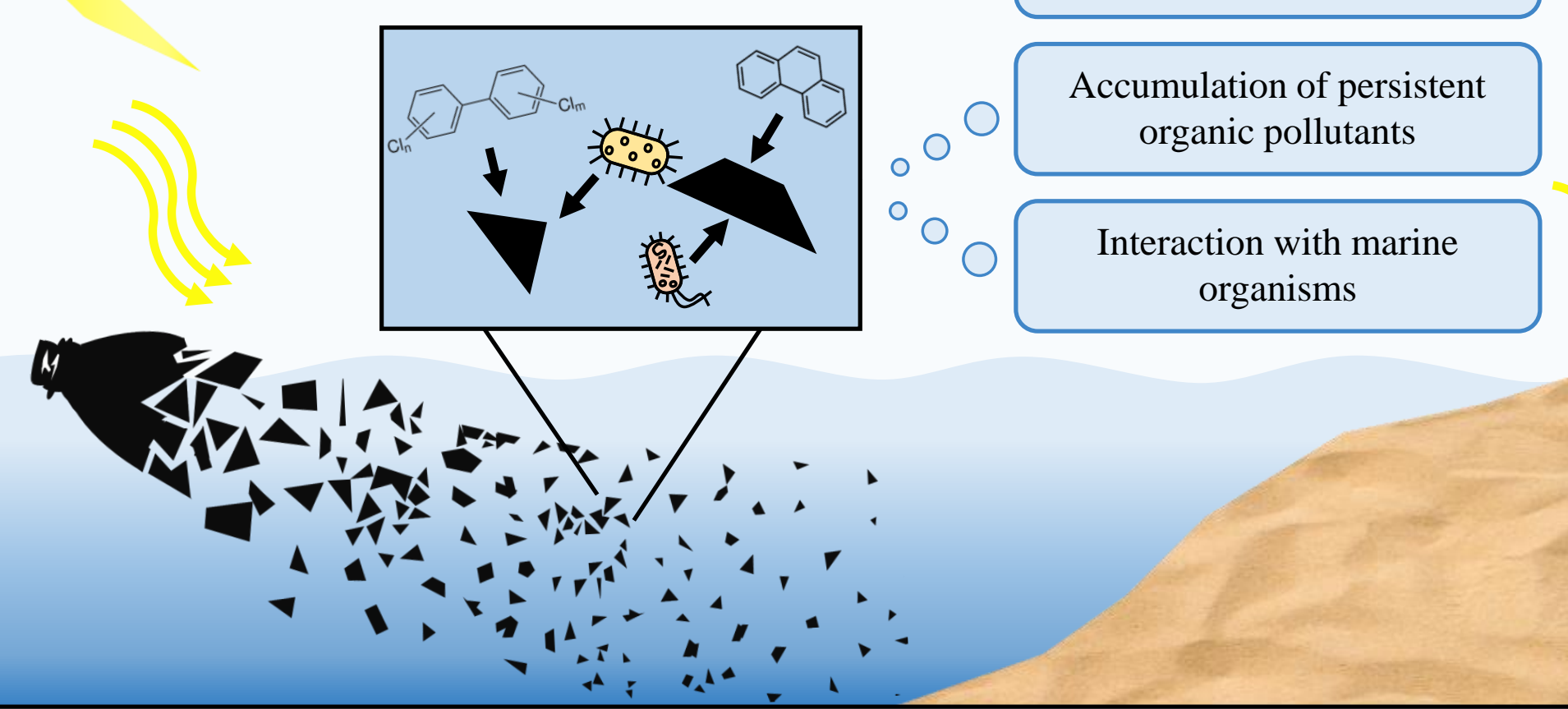

Surface oxidation, cracking and fragmentation
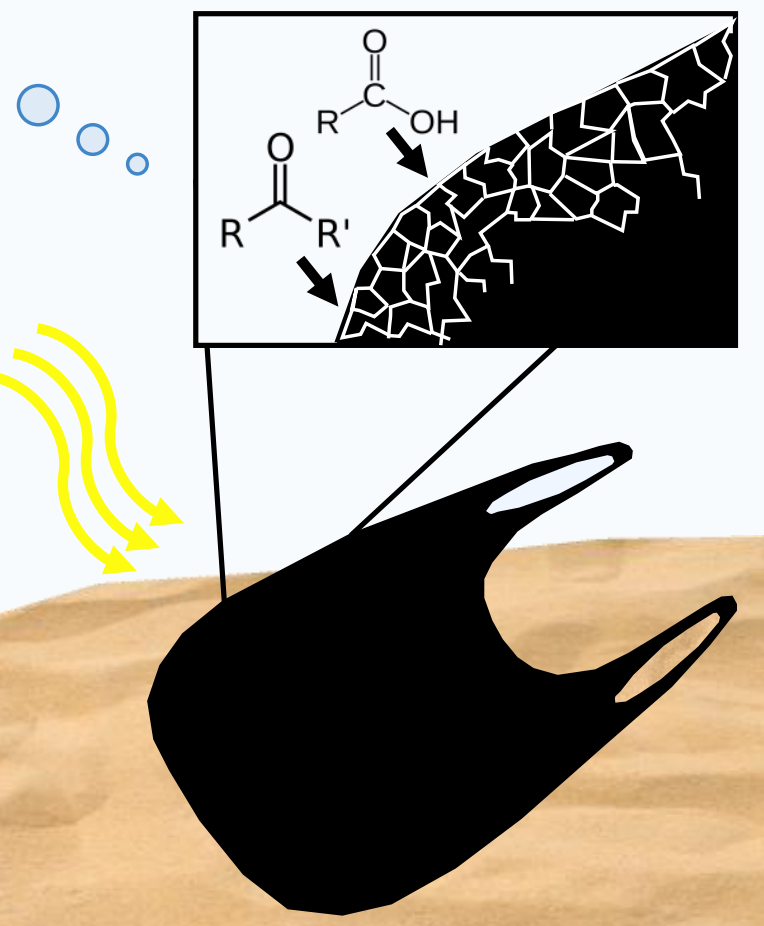


\section{Highlights}

Plastics exposed to sunlight undergoes visual and physico-chemical modifications.

Exposure medium (air/water) highly affects the photodegradation process.

Fragmentation depends on polymer type, formulation, exposure conditions.

The path and time spent by the plastic in the environment cannot be identified yet.

Plastics risk is associated to organic pollutants and degradation products. 


\section{Characteristics, fate, and impact of marine plastic debris exposed to sunlight: a} 2 review.

3 Maria Masry $^{\mathrm{a}}$, Stéphanie Rossignol ${ }^{\mathrm{a}}$, Jean-Luc Gardette ${ }^{\mathrm{b}}$, Sandrine Therias ${ }^{\mathrm{b}}$, Pierre-Olivier Bussière ${ }^{\mathrm{b}}$ and Pascal

4 Wong-Wah-Chung ${ }^{\mathrm{a}^{*}}$

5 a Aix Marseille Univ, CNRS, LCE, Marseille, France

6 b Université Clermont Auvergne, CNRS, UMR 6296, Université Blaise Pascal, Institut de Chimie de Clermont7 Ferrand (ICCF), 8 Avenue Blaise Pascal, TSA 60026, CS 60026, 63178 Aubière cedex, France

8 Authors

9 Maria Masry: maria.masry@univ-amu.fr

10 Stéphanie Rossignol: stephanie.rossignol@univ-amu.fr

11 Jean-Luc Gardette: luc.gardette@uca.fr

12 Sandrine Therias: sandrine.therias@uca.fr

13 Pierre-Olivier Bussière: pierre-olivier.bussiere@sigma-clermont.fr

\section{*Corresponding author: Pascal Wong-wah-chung \\ e-mail: pascal.wong-wah-chung@univ-amu.fr}

Phone: Tél: +33(0)4 42908402

Adress: Aix-Marseille Université - Laboratoire Chimie de l'Environnement (LCE), UMR 7376- Equipe TRAMEEuropôle de l'Arbois- Bât. Villemin, BP 80- 13545 Aix-en-Provence Cedex 4

\section{Abstract}

The increase of plastic production from the middle of the twentieth century was inevitably followed by an increase in the amount of plastic dumped in the natural environment. There, the plastic debris are exposed to sunlight, temperature, humidity, and physical stress. This can induce photo-oxidative and thermal degradation. This review discusses the mechanism of plastics UV weathering and its characteristics. Comparison of the photodegradation rate and physico-chemical properties are made according to the weathering mode (natural/accelerated) and medium (air/water). Since the photodegradation can lead to plastics fragmentation, this phenomenon is described along with the methodologies used in literature to evaluate the fragmentation. The impact of the photodegraded plastic debris on the marine environment is also presented in term of (i) photodegradation 
products and stabilizers leakage, (ii) organic pollutants accumulation, transfer, and leakage, and (iii) toxicity on marine organisms.

\section{Keywords}

Plastic debris, photochemistry, marine environment, oxidation, fragmentation, analytical techniques.

2. Photodegradation mechanism and characteristics of weathered marine plastic debris

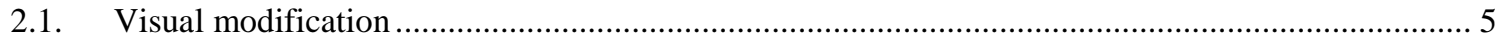

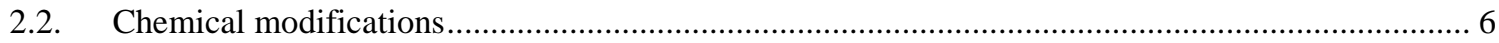

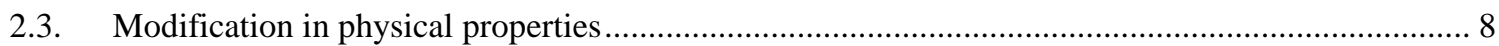

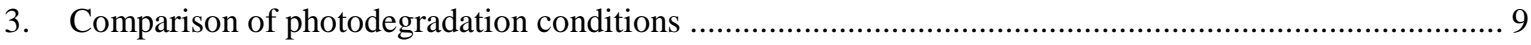

3.1. Photodegradation conditions: natural vs. accelerated weathering ......................................... 10

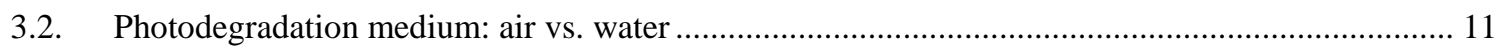

4. Fate of plastic debris: Fragmentation and dissolution................................................................... 13

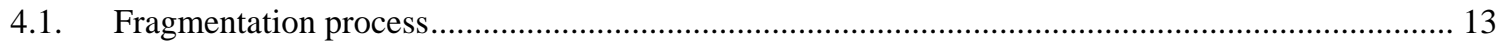

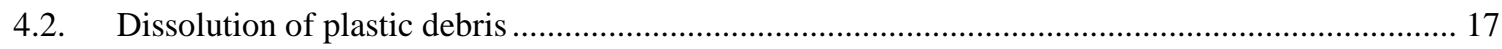

5. Impact of photodegraded plastic debris on the marine environment ................................................ 18

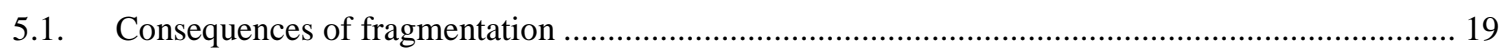

5.2. Photodegradation products, additives and stabilizers leakage ............................................ 19

5.3. Organic pollutants accumulation, transfer, and leakage .......................................................... 20

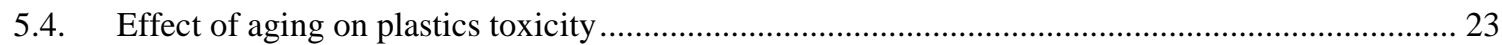

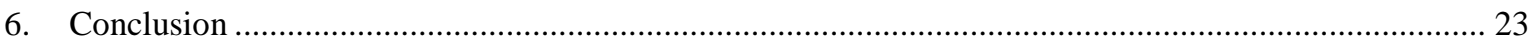

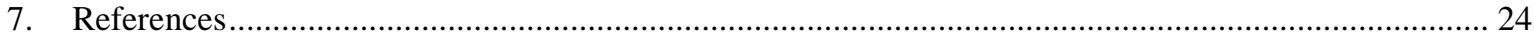




\section{Introduction}

Mass production of plastics began as early as 1939, and increased year by year ever since. Plastic can be categorized according to different criteria, the first being in thermoplastics and thermosets. Thermoplastics can be melted at high temperature and hardened when cooled, like polyethylene (PE), polypropylene (PP), polyvinyl chloride (PVC), polyethylene terephthalate (PET), polystyrene (PS), and acrylonitrile butadiene styrene (ABS). Thermoset plastics, after they were heated and formed remain in a permanent solid state like polyurethane (PU), unsaturated polyester and epoxy resins. Another plastics classification is based on its source as it can be of fossil origin, renewable or even mineral base. According to their structure, polymers can also be classified into carboncarbon backbone and polymers with heteroatoms in their main chain (Brydson, 1999; Geyer, 2020; Van der Vegt, 2002). During compounding and shaping, stabilizers can be added to improve plastics stability and mechanical properties (Brydson, 1999). Being lightweight, durable, strong, and cheap, plastics production increased rapidly.

In 2019, 368 million tons of plastic and 73.5 million tons of synthetic fibers were produced worldwide, China being the biggest plastic producer contributing with $31 \%$ of the world's production. It is estimated that global annual primary plastic production would reach 1.1 billion tons in 2050 . Plastic is mostly used in the packaging industry and in building and construction. Most used plastics are PP, PE, and PVC (Geyer, 2020; Industrievereinigung Chemiefaser, 2020; Plastics Europe, 2020). The life cycle of a plastic product can vary according to the plastic's type and its properties as not all plastic products have the same service life. Depending on its use the plastic's lifespan can vary from less than a year to more than 50 years. Giving this, the amount of plastic waste collected does not correlate with the plastics production of the same year. For example, in Europe in 2018, 61.8 million tons were produced, and only 29.1 million tons of post-consumer plastic waste were collected. Collected waste was recycled, used for energy recovery, or dumped in landfills. Another part of plastic waste is not collected, this is due to littering and unauthorized dumping. Following the actual trends, by 2050 humankind would have generated 33,000 Mt of total plastic waste and that 12,000 Mt of the waste would be in landfills, dumps, or the natural environment (Geyer, 2020; Kosior and Mitchell, 2020; Plastics Europe, 2019a, 2019b; Welden and Lusher, 2020).

Plastic debris are transferred into the marine environment from coastal and inland sources transported by rivers, drainage systems or human activity (Auta et al., 2017; Peng et al., 2020). Jambeck et al. 2015 estimated that between 4.8 and 12.7 million tons of plastic entered the ocean from coastal environments in 2010 (Hurley et al., 2020; Jambeck et al., 2015; Lebreton et al., 2017; Schmidt et al., 2017). Currently, it is estimated that between 5 
and 50 trillion plastic pieces afloat at sea (Eriksen et al., 2014; van Sebille et al., 2015). Most of these particles are more likely to be PE, PP, PS, polyester and polyamide and acrylic (Erni-Cassola et al., 2019).

In the marine environment, plastics are exposed to sunlight, temperature, humidity, physical stress, and microorganisms. This can induce photo-oxidative, thermal, mechanical, and bio-degradation (Andrady, 2011; Gewert et al., 2015; Jacquin et al., 2019).

It is generally considered that radiation in the ultraviolet (UV) and visible is the primary factor in outdoor polymer weathering. Effects from heat, moisture, pollutants, mechanical stresses, and biological attack can come into play, but usually the weathering process begins with a photochemical event (Pickett et al., 2008; White, 2006). Giving the importance of photooxidation for determining the fate and impact of plastic debris, the aim of this work is to give an overview on plastics photodegradation in the marine environment. This study presents the mechanism of plastics photodegradation and its characteristics according to weathering conditions and medium (air/water). The study also details the fragmentation and dissolution processes of plastics exposed to UV weathering. The second focus of this review is on the impact of photodegraded plastic debris on the marine environment in terms of photodegradation products and stabilizers release, accumulation of organic pollutants, and their toxicity on marine organisms.

\section{Photodegradation mechanism and characteristics of weathered marine plastic debris}

In the marine environment, plastics are exposed to several stresses including solar ultraviolet (UV) radiation. The mechanisms by which polymers photodegrade in the presence of oxygen consist of three main steps (initiation, propagation, and termination) and have been the object of numerous articles, reviews, and books (Allen and MacKellar, 1980; Billingham, 1993; Bolland, 1949; Feldman, 2002; Fotopoulou and Karapanagioti, 2017; Gardette, 2000; Gewert et al., 2015; Norrish and Bamford, 1936; Rabek, 1995; Singh and Sharma, 2008). Thus, the mechanism will be discussed briefly.

Photodegradation is initiated by the absorption of UV light and the formation of free radicals. For example, intrinsic and extraneous chromophore groups and/or impurities in polymers can absorb light in the near UV and induce photodegradation (Allen and Fatinikun, 1981; Bolland, 1949; Rånby, 1989). The propagation reactions are common to all carbon backbone polymers, as free polymer radical reacts with oxygen to form peroxyl radicals then hydroperoxides. Further radical reactions with oxygen and polymer radicals take place leading to random chain scission, chain branching, cross linking and formation of oxygen containing functional groups (Agboola et 
al., 2017; Gardette et al., 2013; Gijsman et al., 1999; Torikai et al., 1986). Termination reaction is the combination of two free radicals leading to non-active stable products and can be promoted by the presence of stabilizers (Fechine et al., 2002; Gijsman, 2017; White and Shyichuk, 2007; Zweifel, 1998).

In short, weathering mechanisms and rates can vary depending on the polymer type, structure, and formulation (presence of additives, fillers, pigments, etc.). The consequences of UV weathering on plastics visual aspect and 115 physico-chemical properties are presented here. Plastic's weathering extent corresponds to the chemical and physical modifications that the plastic undergoes according to its UV exposure time and external weathering conditions. It is not an absolute criteria nor a given value to be determined, but rather a relative criteria allowing the comparison of the aging extent of different plastic samples as it can be defined by one or several parameters according to the study.

\subsection{Visual modification}

Plastic's colour could give an indication about its source and the time it has remained in the environment. In international pellet watch campaigns in coastal waters and remote islands, volunteers noticed a yellowish colour on weathered pellets, specially initially transparent and white pellets (Frias et al., 2010; Heskett et al., 2012; Le et al., 2016; Mizukawa et al., 2013; Ogata et al., 2009). Other authors described a discoloration in previously coloured weathered plastic debris as well as loss of gloss and texture, smoothing and denudation as shown in figure 1 (Bandow et al., 2017; Gauquie et al., 2015; Karkanorachaki et al., 2018; Turner et al., 2020).

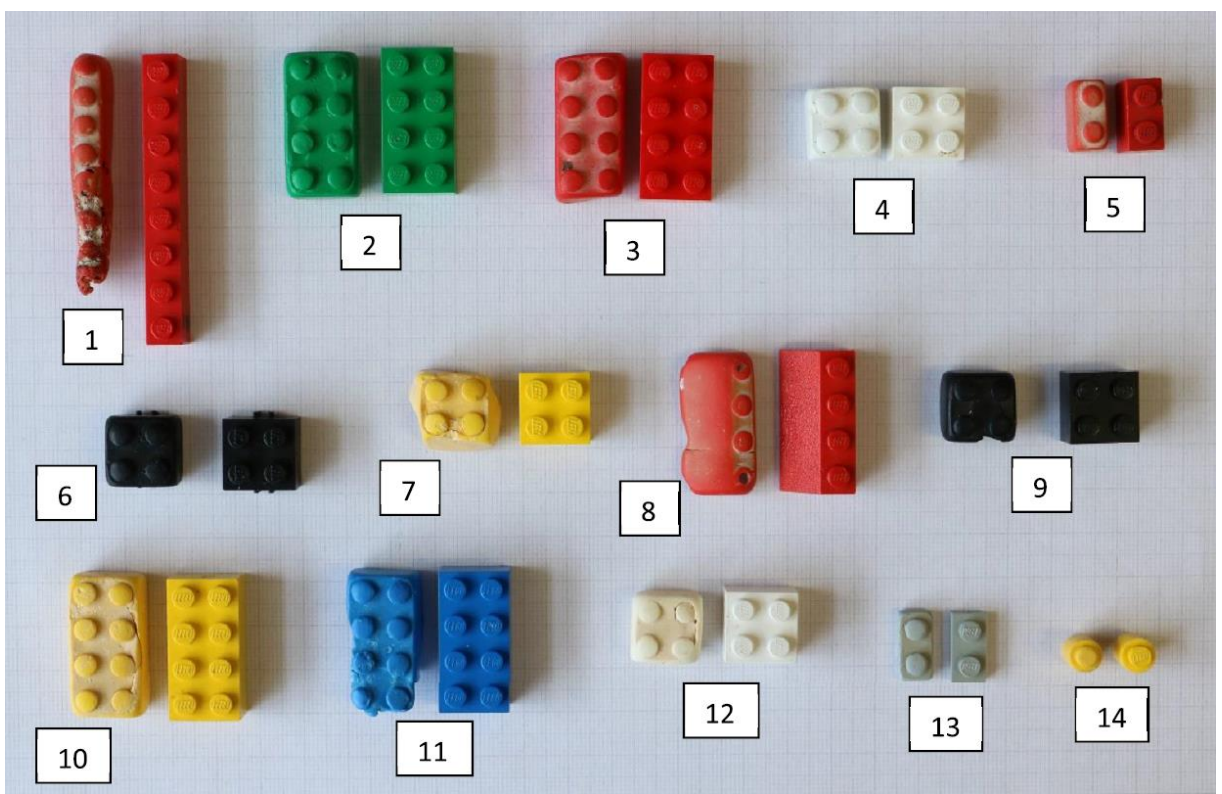

Figure 1: Weathered and unweathered blocks paired from appearance (Turner et al., 2020). (double/colour) 
In the case of previously coloured plastic, loss of colour can be attributed to the loss of organic and/or inorganic colorants, pigments, or dyes due to their photodegradation or diffusion from the plastic matrix to the water. The yellowing can be attributed to chemical modifications and the formation of unsaturated organic groups capable of absorbing wavelengths in the visible region after being exposed to sunlight.

\subsection{Chemical modifications}

The ageing of polymers produces modification of the chemical structure of the polymer due to the formation of a complex mixture of different oxidation products. In many cases, photodegradation mostly occurs at the surface of the polymer, as a result of a control by oxygen diffusion or by the penetration of UV light, and it can be limited in the bulk (Gardette, 1993; Jouan and Gardette, 1987; Malajati, 2009; Pospíšil et al., 2006; Shyichuk et al., 2003, 2005; Sinturel et al., 1999). Depending on the polymer and on the weathering conditions (irradiance, temperature, oxygen permeability etc.) the thickness of the degraded layer can be limited to a few tens of microns or even less (Malajati, 2009; Nagai et al., 2003; Pospíšil et al., 2006; Rivaton et al., 2005; Sinturel et al., 1999). The identification and quantification of the oxidation products are essential for the understanding of the mechanism of degradation and to determine the weathering extent of plastic debris.

The formation of the oxidation products leads to modifications of the infrared spectrum of the polymer and infrared spectroscopy has been recognized for a long time as a very useful tool in the identification of marine plastic debris and in the characterization of the chemical modifications provoked by ageing (Jung et al., 2018, 2018; Lobo and Bonilla, 2003; Pavia et al., 2008; Rugg et al., 1954). It can analyse plastic particles as small as 10 $\mu \mathrm{m}$ and was used in numerous marine plastics sampling campaigns (Bouhroum et al., 2019; Corami et al., 2020; Heskett et al., 2012; Hildebrandt et al., 2020; Mecozzi et al., 2016; Rios et al., 2010, 2007; Scircle et al., 2020; Silva et al., 2018; Syakti et al., 2018, 2017; Thermo Fisher Scientific, 2018).

According to the sample size and thickness either transmission mode or attenuated total reflectance module can be applied to acquire the sample spectra (Skoog et al., 2007). For polyolefins, two main areas are correlated with the formation of the photodegradation products: hydroxyl groups $(\mathrm{O}-\mathrm{H})$ with a broad peak from 3100 to 3700 $\mathrm{cm}^{-1}$ and carbonyl bands $(\mathrm{C}=\mathrm{O})$ from 1550 to $1810 \mathrm{~cm}^{-1}$ consisting mainly of carboxylic acids, ketones, esters and lactones at 1713, 1720, 1735, and $1780 \mathrm{~cm}^{-1}$, respectively (Bandow et al., 2017; Brandon et al., 2016; Gardette et al., 2013; Lemaire et al., 1996; Lv et al., 2015; Pavia et al., 2008; Rouillon et al., 2016). 
In figure 2, an infrared spectrum is presented showing an increase of absorbance in the region relative to

carbonyl bands representing the degradation products of polypropylene (PP). Even though other areas can be selected to characterize the weathering extent according to polymer type, the carbonyl band is largely employed to characterize the UV weathering extent of common polymers such as PVC, PS, PLA, PET and ABS (Bandow et al., 2017; Brandon et al., 2016; Copinet et al., 2004; Gardette, 2000; Ioakeimidis et al., 2016; Liu et al., 2019; Turner et al., 2020).

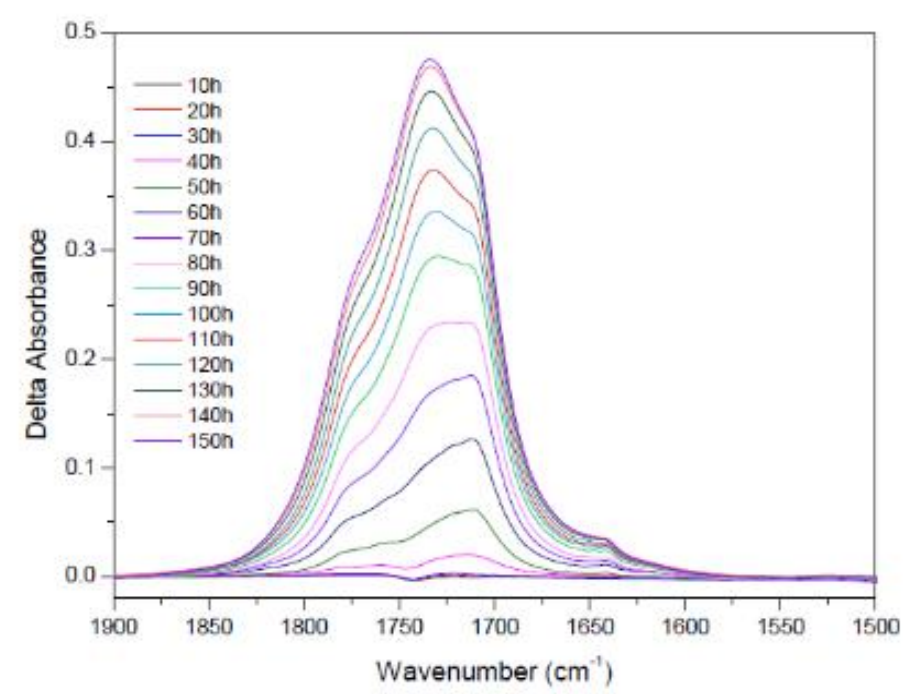

Figure 2: Infrared spectra in the region $1900-1500 \mathrm{~cm}^{-1}$ of a photooxidized PP film (Rouillon et al., 2016). (single/color)

The chemical composition of plastic debris can also be determined by X-ray Photoelectron Spectroscopy (XPS) and Energy Dispersive X-Ray Spectroscopy (EDS or EDX). These methods can give details about the elemental composition of the sample's surface. For example, chlorine and carbon are the most abundant elements in the PVC's surface. XPS and EDS results on UV aged plastics shows that weathered plastic's surface contains higher oxygen content than unaged plastics confirming FTIR results (Gniadek and Dąbrowska, 2019; Massey et al., 2007; Müller et al., 2018; Tian et al., 2019; Tiwari et al., 2019; Turner et al., 2020; Wang et al., 2017; Yang et al., 2003).

Among the chemical consequences of UV weathering on plastic debris, changes in some polymer structures are cited in addition to the formation of oxidized function. This can be further examined by Raman spectroscopy. Raman spectroscopy allows the identification of plastics based on characteristic peaks in their specific fingerprint region. According to the polymer type, photodegradation mechanism and weathering extent changes in the Raman spectra can occur. For some polymers such as PE, PP and PET characteristic peaks in the fingerprint region do not show considerable changes with weathering, while for other polymers changes can be noticed. For example, the 
spectrum of UV weathered PVC shows an intensity reduction for its characteristic bands at 693 and $637 \mathrm{~cm}^{-1}$ compared to unaged PVC corresponding to $\mathrm{C}-\mathrm{Cl}$ bond of the polymer. Even though Raman spectroscopy presents a wider spectral range coverage, better resolution, lower water interference and can analyse smaller plastic particles (down to $100 \mathrm{~nm}$ ) when compared to FTIR, it has a limitation in the analysis of photodegraded samples. Thus, for the analysis of photodegraded polymers, reference spectra of photodegraded polymers should be included in Raman database (Chabert et al., 1997; Lenz et al., 2015; Ribeiro-Claro et al., 2017; Silva et al., 2018; Sobhani et al., 2020).

Pyrolysis-Gas Chromatography-Mass Spectrometry (Py-GC-MS) is also described in literature for the identification of polymer type and associated organic stabilizers by analysing their thermal degradation products (Fischer and Scholz-Böttcher, 2017; Fries et al., 2013; Hermabessiere et al., 2018). This method will not be further discussed here since it is mostly used to identify microplastics and not their weathering extent. Nevertheless, it could be interesting to develop this method by creating a database for chemically aged polymers.

While it is not frequently used for environmental plastic sample's analysis, Gel Permeation Chromatography (GPC) is used in laboratory analysis to characterize plastics before and after UV weathering. GPC gives information about the molecular weight distribution including weight and number average molecular weights. Polymers studied after UV exposure showed a decrease in their molecular weight distribution to low molecular weight side due to chain scission mechanism (Ceccarini et al., 2018; Copinet et al., 2004; Goedecke et al., 2017; Hiejima et al., 2018; Lv et al., 2015; Müller et al., 2018; Shyichuk et al., 2005; ter Halle et al., 2017). Even though environmental plastic debris can be characterized by GPC, a limitation remains in the determination of the weathering extent as the molecular weight distribution of the initial plastic is more often unknown.

\subsection{Modification in physical properties}

Surface modification of UV weathered plastics is not limited to the formation of oxidation products as the fragilization of polymer structure can induce changes in the surface topography. While unaged plastics show a smooth surface, as presented in figure 3, the surface of UV weathered plastic presents mostly cracks and fractures, as well as flakes, grooves, adhering particles, and pits. In the case where a plastic is exposed to the same external conditions, the surface degradation should increase with the UV exposure time (Cooper and Corcoran, 2010; Corcoran et al., 2009; Girão et al., 2017; Liu et al., 2019; Lv et al., 2015; Rouillon et al., 2016; ter Halle et al., 2017, 2016; Turner et al., 2020). For this, Scanning Electron Microscopy (SEM) is suitable to acquire highmagnification images of plastic particles with a good resolution. 


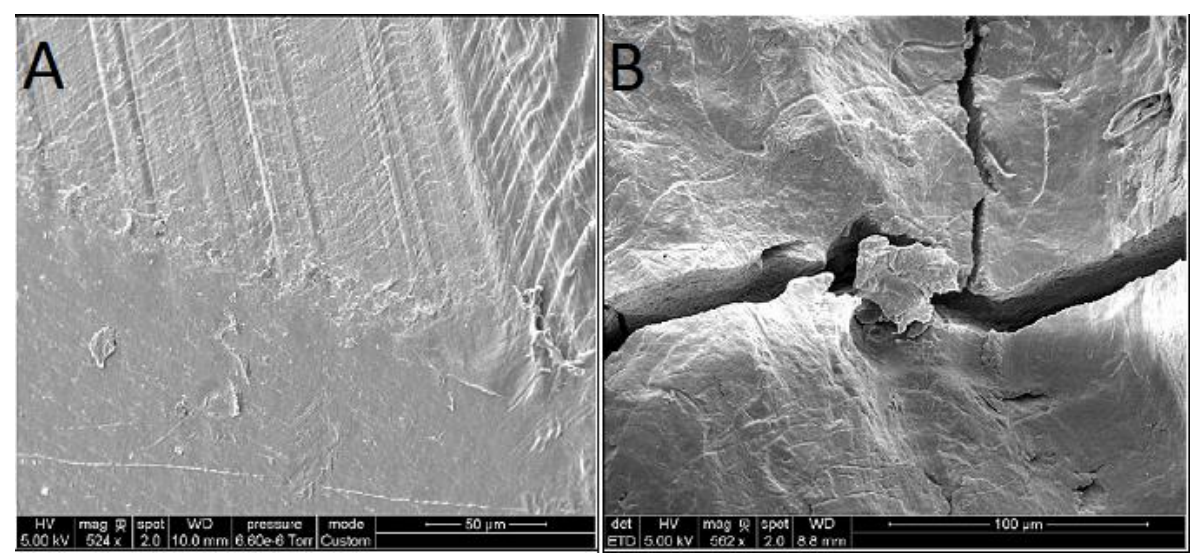

Figure 3: SEM images of (A) an unaged PE pellet and (B) a PE sample collected from the North Atlantic subtropical gyre (ter Halle et al., 2017). (double)

Atomic force microscopy (AFM) is another microscopic technique to acquire plastics surface topographies. It is mainly applied in laboratory studies to evaluate the surface condition of the photodegraded plastic before and after the application of a physical force, for example during Vickers micro-hardness test (Larché et al., 2012; Rouillon et al., 2016). Although environmental plastic samples have been rarely characterized by AFM, recent studies showed an interest for this technique to characterize environmentally weathered plastics as results showed a significant increase in the root-mean-square roughness by at least a factor 2 (Rowenczyk et al., 2020; Taghavi et 215 al., 2021)

Plastic's density, buoyancy and location in the water column and thus exposure to UV light depends on its structure and crystallinity. Many studies concerning semi-crystalline plastic's properties during UV aging documented an increase of the crystallinity. This is explained by the fact that oxidation occurs in the amorphous phase, as oxygen cannot penetrate into the crystalline phase. Oxidation can lead to an increase of crystallinity resulting of chemi-crystallisation (crystal growth from molecules segments released by the scission of polymer chains), which is responsible for a higher density, thus a negative buoyancy for plastic debris (Rabello and White, 1997). This is confirmed in environmental conditions, as marine plastic debris show a higher crystallinity, estimated by Differential Scanning Calorimetry (DSC). compared to consumer packaging materials (Andrady, 2017; Lv et al., 2015; Müller et al., 2018; Pospíśil et al., 2006; Rouillon et al., 2016; ter Halle et al., 2017).

\section{Comparison of photodegradation conditions}

The influence of factors such as radiation intensity and temperature on the degradation of polymers provoked by UV-exposure has been determined for both natural and accelerated weathering (Lemaire et al., 1996, 1979). 
Nevertheless, in the marine environment, other factors such as mechanical strain, humidity, oxygen availability, weather conditions, and bacterial fouling can interfere and differ for beaches, surface water, deep-water and marine sediments (Andrady, 2017; Andrady et al., 2019; Beltrán-Sanahuja et al., 2020; Kockott, 1989). While several studies compared natural and accelerated weathering, there have been limited studies on the degradation of plastic debris in the marine environment.

\subsection{Photodegradation conditions: natural vs. accelerated weathering}

Natural weathering being time consuming and depending of several factors that are difficult to control, alternative methods are used to accelerate weathering in controlled conditions (Andrade et al., 2019; Avenel et al., 2017; Gardette, 2000; Malajati et al., 2011). Most publications in literature used accelerated weathering simulating natural conditions in order to estimate the lifetime of plastic materials according to their physicochemical and mechanical properties (Al-Salem, 2009; Al-Salem et al., 2019; Espí et al., 2007; Feldman, 1981). Natural weathering conditions varies according to regions, climates, and seasons while accelerated weathering was according to different conditions applied in commercial chambers such as Q-Panel, Atlas Weather-Ometer, SEPAP 12-24 and SPHERE with dry or wet/dry cycle depending on the study (Fairbrother et al., 2019; Gugumus, 1995; Larché et al., 2011; Lv et al., 2015; Philip and Al-Azzawi, 2018; Pimentel et al., 2005; Pimentel and Gardette, 2001; Rosa et al., 2005; Scoponi et al., 2000; Tidjani, 2000, 1996; Tuasikal et al., 2014; White et al., 2011; Wypych, 1990).

It is important in accelerated weathering experiments to simulate as closely as possible natural weathering. This requires that the various degradation products be produced at the same proportions and the mechanical properties modifications comparable for both weathering modes. Several publications compared the effects of natural and accelerated weathering at different exposure times with regular characterization. Some correlation can be made to plastic debris weathered in the marine environment at shore and in water (Gardette, 2000; Gewert et al., 2015). The higher radiation dose, temperature and humidity in accelerated weathering cause faster chain scission rate and crack growth increasing the area exposed to UV radiation (Andrady, 1989; Kockott, 1989; Maxwell et al., 2005; Philip and Al-Azzawi, 2018). Thus, the accelerated weathering presented an acceleration rate ranging overall from 2.5 to 30 times the natural weathering depending on the polymer type, the region and accelerated conditions used. It is worth noting that limits to acceleration may exist above an irradiance threshold due to the fact that recombination and/or disproportionation become predominant compared to realistic propagation (Therias et al., 2021). This was demonstrated for PE samples and we can infer that such threshold 
depends on the polymer type. In addition, the same authors showed that temperature affects the photooxidative degradation rate of PE with a measured apparent activation of $74 \mathrm{~kJ} / \mathrm{mol}$ (Therias et al., 2021). In the case of PP, an activation energy for photooxidation around $55 \mathrm{~kJ} / \mathrm{mol}$ had been determined (Audouin et al., 1998). The consequence is that, with an activation energy of $74 \mathrm{~kJ} / \mathrm{mol}$, an increase of temperature from 50 to $60^{\circ} \mathrm{C}$ would double the rate of photooxidation, and the rate would be multiplied by a factor 5 when passing from 40 to $60^{\circ} \mathrm{C}$. Thus, the variability of temperature by region is an important parameter that should be considered, but difficult to be predicted. The rate of photooxidation of a given polymer is then expected to present strong variations depending on the location, the season, and the hour, with very important oxidation rates with higher temperatures. In other applications where temperature plays an important role on the photodegradation, i.e. solar mirrors industry, empirical models have been established to take into account how the variations of temperature and the reached maximum temperature impact the degradation (Avenel et al., 2018; Escobar and Meeker, 2006).

\subsection{Photodegradation medium: air vs. water}

From an environmental point of view, some authors have described and compared UV weathering in air (beach) and water (ocean surface) (Andrady, 2011; Biber et al., 2019; Cai et al., 2018; Malajati et al., 2011; Pimentel et al., 2005; Ranjan and Goel, 2019; Tang et al., 2019, 2018). These approaches were essential to have a better understanding of the weathering process at shore and in the ocean and to estimate the duration spent by plastic debris in the environment.

Authors essentially compared plastic debris characteristics in four different exposure conditions, air-UV light, air-darkness, water-UV light, and water-darkness. Plastics were weathered in natural or accelerated conditions at different exposure times. Plastics used in these studies were mostly PP, PE, PET, PS and PVC as pellets or films.

According to FTIR results for polyolefins (based on carbonyl and hydroxyl groups absorption bands), PET and $\mathrm{PVC}$, the level of chemical weathering was higher in air in comparison to water, as air has higher oxygen content and UV transmittance opposed to water. The slower degradation rate in water is also due to the lower temperature (Andrady, 2011; Biber et al., 2019; Cai et al., 2018; Pimentel et al., 2005; Ranjan and Goel, 2019; Tang et al., 2019, 2018). The lower concentration of carbonyl and hydroxyl groups in plastics weathered in water can also be due to the release of the degradation products into the water (c.f. section 4.2). Thus, infrared analysis of the solid polymer can be subject to errors in determining quantitatively the photodegradation state of marine plastic debris as the concentrations of some photoproducts could be underestimated as a consequence of the migration of these products. The other characterization methods used presented complementary results to those of FTIR. Although 
Raman spectra did not show significant changes for the weathering of plastics in different mediums, they did show differences between unaged and weathered plastics. SEM and AFM analysis confirmed the presence of fractures and holes on the plastic's surface, similarly in both mediums. Nevertheless, mechanical properties decreased more for plastics exposed in air than those exposed in water (Andrady, 1989; Andrady et al., 1993; Biber et al., 2019; Brandon et al., 2016; Cai et al., 2018; Pimentel et al., 2005; Ranjan and Goel, 2019; Tang et al., 2019, 2018).

Opposite results occurred in the case of PS, as its photodegradation was faster in water in comparison to air.

The authors concluded that this is possibly due to the removal of the oxidized yellow surface by water movement allowing the bulk beneath to be gradually exposed to UV radiation while in the air this layer prevents the UV light diffusion and protects the bulk (Andrady and Pegram, 1991; Tian et al., 2019). A summary of polymer behaviour according to the weathering medium is presented in Table 1.

Table 1: Qualitative comparison of polymer behaviour in term of weathering extent in air / water medium (IR carbonyl and hydroxyl groups bands) (Biber et al., 2019; Cai et al., 2018; Pimentel et al., 2005; Ranjan and Goel, 2019; Tang et al., 2019, 2018), fragmentation (number of generated fragments) (Kalogerakis et al., 2017; Lambert and Wagner, 2016a; Song et al., 2017; Weinstein et al., 2016) and dissolution (mass of plastics and dissolved organic carbon) (Lee et al., 2020; Ward et al., 2019; Zhu et al., 2020). Symbols: ++ resistant, -- fragile and x not mentioned.

\begin{tabular}{|l|c|c|c|c|}
\hline & Air UV & Water UV & Fragmentation & Dissolution \\
\hline PE & + & ++ & ++ & ++ \\
\hline PP & + & ++ & ++ & + \\
\hline PS & - & -- & -- & - \\
\hline PET & + & ++ & ++ & $\mathrm{x}$ \\
\hline PLA & $\mathrm{x}$ & $\mathrm{x}$ & - & $\mathrm{x}$ \\
\hline PVC & + & ++ & $\mathrm{x}$ & \\
\hline
\end{tabular}

Fewer studies compared weathering behaviour in water with different salt content. FTIR and mechanical characteristics results of PE, PP and PS showed that the photodegradation rate of plastics in ultrapure or freshwater was higher than that in seawater. This is due to the salt content as the refractive index of water increase with salinity, thus the UV photonic flux for plastics in seawater is lower compared with that in pure water. Another reason can be the formation of salt crystals on plastic surface that can protect the bulk from UV radiation (Cai et al., 2018; Ranjan and Goel, 2019).

Some authors compared their results with environmental plastic debris to estimate how long it has been in the ocean. Brandon et al. 2016 recorded hydroxyl and carbonyl infrared bands in different plastic samples exposed to sunlight in seawater as a function of time. They did not obtain linear results, bond indices showing systematically increasing and decreasing phases under such conditions. The combination of both formation and water release and 
312 / or photodegradation of the oxidized species could explain these observations. The authors concluded that this approach presents a limitation for determining the weathering extent and the time spent in the environment by a plastic. Nevertheless, they were be able to estimated that samples from California and the North Pacific subtropical gyre were exposed for less than 18 months with some exposed for less than 30 months (Brandon et al., 2016). This approach thus allowed them to estimate a period of time in which the plastic was exposed to sunlight in the marine environment but not the exact weathering time nor the path undertaken by the plastic in the environment.

Despite the current knowledge, it is therefore still hard to determine how long a given plastic has been in the environment. Moreover, the degradation depends not only on the polymer type, its characteristics, and its initial stabilizer formulation but also on the path of the plastic from its source to the ocean. In fact, before entering the ocean, the plastic can be protected from ageing for years, or it can be weathered during its use or on shore. Also, biofilms development onto the plastic surface in the ocean can protect it from sunlight and thus from photodegradation. Better understanding of the longer term, natural weathering and the variable conditions of the weathering process is still needed.

\section{Fate of plastic debris: Fragmentation and dissolution}

As already mentioned, UV exposure can lead to the oxidation of the plastic surface and its embrittlement, after this, mechanical forces caused by wind action, current and tides can induce fragmentation and / or dissolution according to environmental conditions and plastic type (Cooper and Corcoran, 2010; O'Brine and Thompson, 2010; Pegram and Andrady, 1989).

\subsection{Fragmentation process}

The fragmentation process is the disintegration of the material, it is described as the degradation of plastic debris into smaller particles. Two fragmentation processes are described in literature and are presented in figure 4: plastic splitting and surface ablation (Andrady, 2017; Yakimets et al., 2004). 


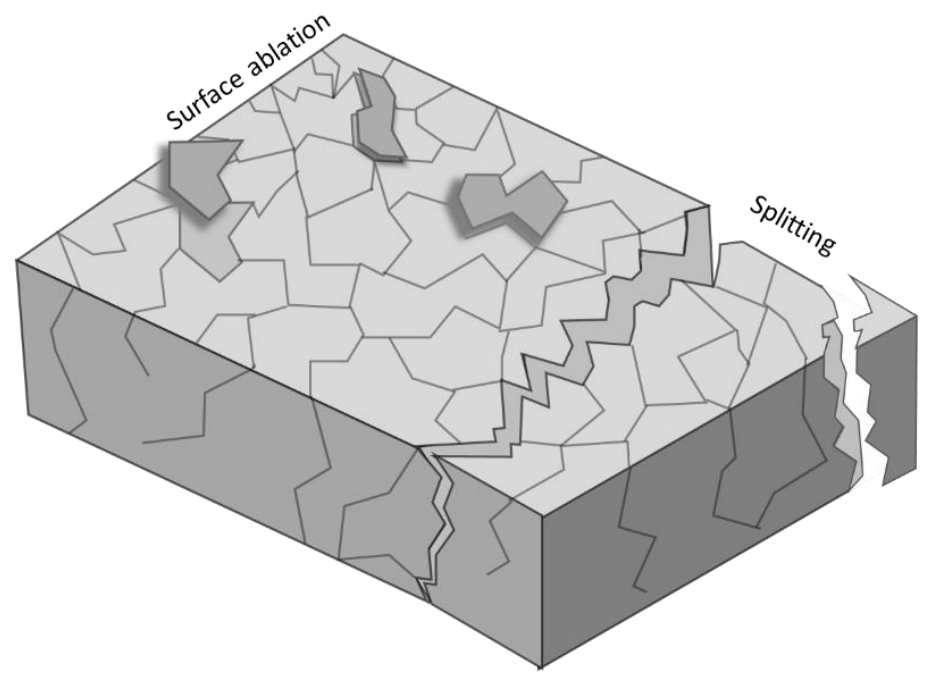

Figure 4: Fragmentation processes. (double)

After the plastic surface was weathered, cracks on the surface can propagate deeper into the plastic and cause the split of the plastic into two or more fragments. This process was described for semi-crystalline polyolefins as they have a heterogeneous surface consisting of crystalline and amorphous phases. After the degradation of the amorphous phase due to UV exposure, cracks develop in inter-crystalline region. In the case of plastic debris exposed to UV in air, fragmentation is not likely to occur without mechanical forces (Song et al., 2017). For water weathered plastics, cracks can propagate through the plastics, and water probably accelerates the propagation of these cracks. Thus, for plastic debris exposed to UV in water, fragmentation can occur without any external mechanical forces (Julienne et al., 2019). Eventually, this process induces the splitting of the plastic, thus to the formation of plastics fragments and secondary microplastics (Andrady, 2017; Julienne et al., 2019; ter Halle et al., 2016).

For surface ablation, the weathered surface of the plastic usually presents different characteristics than the bulk of the material and is more susceptible to mechanical stress as repeated wet and dry cycles fragilize the interface between the surface and the bulk which can cause fragmentation by surface ablation (Andrady, 2017; Feldman, 2002). An example for this type of weathering was described as oxidized PS surface layer is removed by water movement leading to the graduate degradation of the plastic's bulk (Andrady and Pegram, 1991). This is also confirmed by SEM analysis of marine plastic debris consisting of PP, PE, PS and PVC as the surface texture of most samples presents pits, conchoidal fractures, linear fractures, subparallel ridges and grooves (Corcoran et al., 2009; Kedzierski et al., 2018; ter Halle et al., 2017). This can generate particles as small as nano-plastics (Gigault et al., 2016). 
Ter Halle et al. 2016 characterized environmental plastic samples from the North Atlantic gyre in order to better understand microplastics fragmentation. The authors suggested that the fragmentation of plastic debris depends on their buoyancy in water: big parallelepipeds float flat at the surface with one face exposed to the sun while smaller cubic pieces tend to roll at water surface. This is confirmed by their SEM results, as $80 \%$ of the parallelepipeds plastics had one face with more cracks than the other while cubic plastics presented the same characteristics on all faces (ter Halle et al., 2016). Corcoran et al. 2009 also sampled environmental plastics. Their SEM and FTIR results indicate that the mechanical process was mostly responsible of the surface erosion and that this process was more favourable when the surface was oxidized from UV exposure (Corcoran et al., 2009). This is confirmed in a lab study by Song et al. 2017 that stated that polymer fragmentation increase with UV exposure time in combination with mechanical abrasion (Song et al., 2017).

Ter Halle et al. 2016 noted that in fragmentation studies the mass of the plastic should be considered and not its size since mass is conservative and unequivocal while size can be dependent of the measuring method (Filella, 2015; ter Halle et al., 2016). Resmeriță et al. 2018 measured weight loss of PP pellets exposed to UV radiation for 500 hours in air and seawater at ocean like conditions (Resmeriță et al., 2018). The author noted that weight loss was more significant in samples weathered in seawater while no significant decrease was noted in samples weathered in air. Despite this, the author was not able to detect any released particles by optical microscopy.

\subsubsection{Comparison of polymers fragmentation behaviour}

Fragmentation rate depends mostly on the polymer type, additives used in compounding, UV exposure medium and mechanical conditions (Song et al., 2017). In general, laboratory fragmentation studies consist of exposing plastic material to natural weathering or accelerated UV degradation combined with mechanical force. Two approaches are described in literature.

The first one consists on the exposure of plastic to natural weathering, for example in a salt marsh habitat for Weinstein et al. 2016, then placing the photodegraded samples in closed seawater amber jug while shaking to induce fragmentation (Weinstein et al., 2016). Since plastic fragments can be lost during weathering in open exposure system, this approach can induce an underestimation of the number of particles produced. Other authors studied the fragmentation in a closed simulated environment. In this second approach, plastic samples are exposed 
to UV light directly in closed simulated beach/ocean environment in laboratories with and/or without mechanical abrasion (Kalogerakis et al., 2017; Lambert and Wagner, 2016a, 2016b; Song et al., 2017).

Plastic types studied were mostly PE, PP, PS, PET and PLA as pellets, films, strips, and consumer materials. After weathering in both approaches, the surface of the plastic is analysed by FTIR and SEM while the fragments generated are collected from sand and/or water and characterized by dissecting scope, particle counter (Coulter counter, nanoparticle tracking analysis) or density separation followed by Nile red stain and fluorescence microscopy (Lambert and Wagner, 2016a; Song et al., 2017; Weinstein et al., 2016).

FTIR results showed in all cases an increase for hydroxyl and carbonyl groups peaks while SEM results showed surface cracks due to photooxidation. For all plastics, identified fragments sizes varied overall from $30 \mathrm{~nm}$ to 1000 $\mu \mathrm{m}$, and the particle size distribution showed an increase in particle concentration with decreasing particle size. For polyolefins, fragmentation did not occur without the mechanical abrasion (Song et al., 2017). They also produced the least number of particles in the smaller size range. This is attributed to the initial composition of the plastic as polyolefins could contain stabilizers, such as anti-UV and antioxidants, that could impede UV degradation compared to PS and PLA (Lambert and Wagner, 2016a; Song et al., 2017; Weinstein et al., 2016).

For example, in the study by Song et al. 2017 and in the size range of $50-1000 \mu \mathrm{m}$, expanded polystyrene (EPS) was the most fragmented and released 10,501 \pm 1718 particles/pellet, the PP $6084 \pm 1061$ particles/pellet, while PE was the least fragmented with $20 \pm 8.3$ particles/pellet (Song et al., 2017). In this study over $73 \%$ of fragments were below $100 \mu \mathrm{m}$ and over $97 \%$ were below $300 \mu \mathrm{m}$. In the case of EPS fragments, around $10^{4}$ particles/pellet were below $100 \mu \mathrm{m}, 1.5$ particles/pellet were at $200 \mu \mathrm{m}$ and less than a 1 particle/pellet were at 1 $\mu \mathrm{m}$. In another study by Lambert and Wagner 2016a in the size range from 2 to $60 \mu \mathrm{m}$, PS and PLA generated the most plastic particles at respectively 92,465 and 61,750 particles $\mathrm{mL}^{-1}$, while PE and PP pellets produced respectively 39,619 and 26,380 particles $\mathrm{mL}^{-1}$ (Lambert and Wagner, 2016a). Data from these studies can only be compared qualitatively, considering the fragmentation order of polymers as presented in Table 1, as a limitation remains in data expression and unit (Hidalgo-Ruz et al., 2012; Lambert and Wagner, 2016a).

Efimiva et al. 2018 and Chubarenko et al. 2020 in two complementary publications studied the effect of bottom marine sediments with different characteristics and grain-size on the fragmentation of unaged single-use plastic (LDPE, PP and PS). They placed plastic with water and sediments in a rotating mixer and characterized generated fragments in term of mass, number, shape, and surface (Chubarenko et al., 2020; Efimova et al., 2018). PS 410 produced the most fragments as it has lost $99.8 \%$ of its initial mass, while PP was the least degraded. In another 
study, Beltrán-Sanahuja et al., 2020 showed that PLA based materials degrade 5 times more in sediment than in water (Beltrán-Sanahuja et al., 2020).

Some publications suggested that plastic debris could be fragmented not only into microplastics but also into nano-sized plastic particles (Andrady, 2017, 2011). In a complementary study, Lambert and Wagner 2016b developed the nano aspect from 30 to $2000 \mathrm{~nm}$ by analysing the fragments produced by PS after accelerated UV exposure in water. In this study, the nano plastics concentration was $1.2 \times 10^{8}$ particles $\mathrm{mL}^{-1}$ with an average particle size of $224 \mathrm{~nm}$ (Lambert and Wagner, 2016b). So far, no lower size limitation was mentioned in literature and several challenges remain concerning the nano fragments detection, identification and quantification (Gigault et al., 2018).

Giving this, fragmentation rate and generated particle sizes depends on the polymer type, shape, composition and on external conditions. In the studies described herein weathering conditions and medium as well as plastics shape differs, thus the tendencies for plastics fragmentation cannot be fully established. More fragmentation research should be done as particle formation may differ according to weathering conditions (Kalogerakis et al., 2017; Lambert and Wagner, 2016a).

\subsection{Dissolution of plastic debris}

Photochemical dissolution of plastic debris was also studied (Ward et al., 2019; Zhu et al., 2020). Ward et al. 2019 studied the dissolution of PS in the marine environment (Ward et al., 2019). They exposed PS samples to accelerated UV weathering and measured $\mathrm{CO}_{2}$ and dissolved organic carbon production. They noted in their main results that UV degradation can oxidize PS completely into $\mathrm{CO}_{2}$ and partially into dissolved organic carbon. According to studies concerning PS photodegradation products, these compounds are likely to be carboxylic acids and ketones (Watanabe et al., 2009; Yuzawa et al., 2013). After their leaking into the water, these hydrophilic products undergo further photodegradation or mineralization (Tian et al., 2019).

In other studies by Zhu et al. 2020 and Lee et al. 2020, post-consumer plastics such as PP, PE and EPS as well as plastic fragments collected from the North Pacific gyre were exposed in fresh and seawater to simulated sunlight and dissolved organic carbon was analysed (Lee et al., 2020; Zhu et al., 2020). Overall, the mass of plastics was reduced, and the dissolved organic carbon showed an increase according to UV exposure time. EPS degraded at a faster rate than PP and PE with PE being the most resistant to dissolution, as presented in Table 1. Surface oxidation was also noticed by FTIR analysis and fragmentation was observed by SEM analysis. The dissolution effect was 
also documented on environmental plastic samples that were analysed by SEM. The presence of pits on the plastic surface was attributed to a dissolution mechanism of the plastic floating at sea (Corcoran et al., 2009).

\section{Impact of photodegraded plastic debris on the marine environment}

Since there is a continuous increase in plastic production and thus in the amount of plastic debris polluting the marine environment, it is essential to understand the impact of these plastic debris on the marine ecosystems.

The first described impact of plastic litter was the entanglement and ingestion of plastics by vertebrates especially sea birds, marine mammals, turtles, fish and other marine biota (Clunie and Hendricks, 1996; Hofman, 1995). Plastic debris affects many species of marine organisms worldwide. The number of organisms identified to be affected is more likely to increase as the effect of micro and nano plastics is being assessed on smaller organisms (Moore, 2008).

Another risk is the toxic chemicals associated with plastic debris (Fred-Ahmadu et al., 2020; Hong et al., 2018). More than 60 pollutants were indeed found in some plastic samples (León et al., 2018). Associated pollutants can be:

- Intentionally added substances (IAS) like stabilizers and additives intentionally incorporated in the plastic during its manufacturing, compounding, or processing.

- Non intentionally added substances (NIAS) for example residual monomers and oligomers, from incomplete polymerization and degradation products of the polymer due to UV, thermal, and mechanical weathering during the plastic's lifetime use or in the marine environment.

- Persistent organic pollutants (POPs) present in the environment and sorbed onto plastic debris.

Plastic's toxicity, in literature is mainly described as associated with the accumulation, transfer, and release of these pollutants, as presented in figure 5. Since the main studied risk of plastic debris is associated with the sorbed pollutants, it is essential to investigate the accumulation (sorption) and leakage (desorption) of these pollutants in marine like conditions (Gallo et al., 2018; Hong et al., 2018; Liu et al., 2020b; Rochman et al., 2014; F. Wang et 462 al., 2018). 


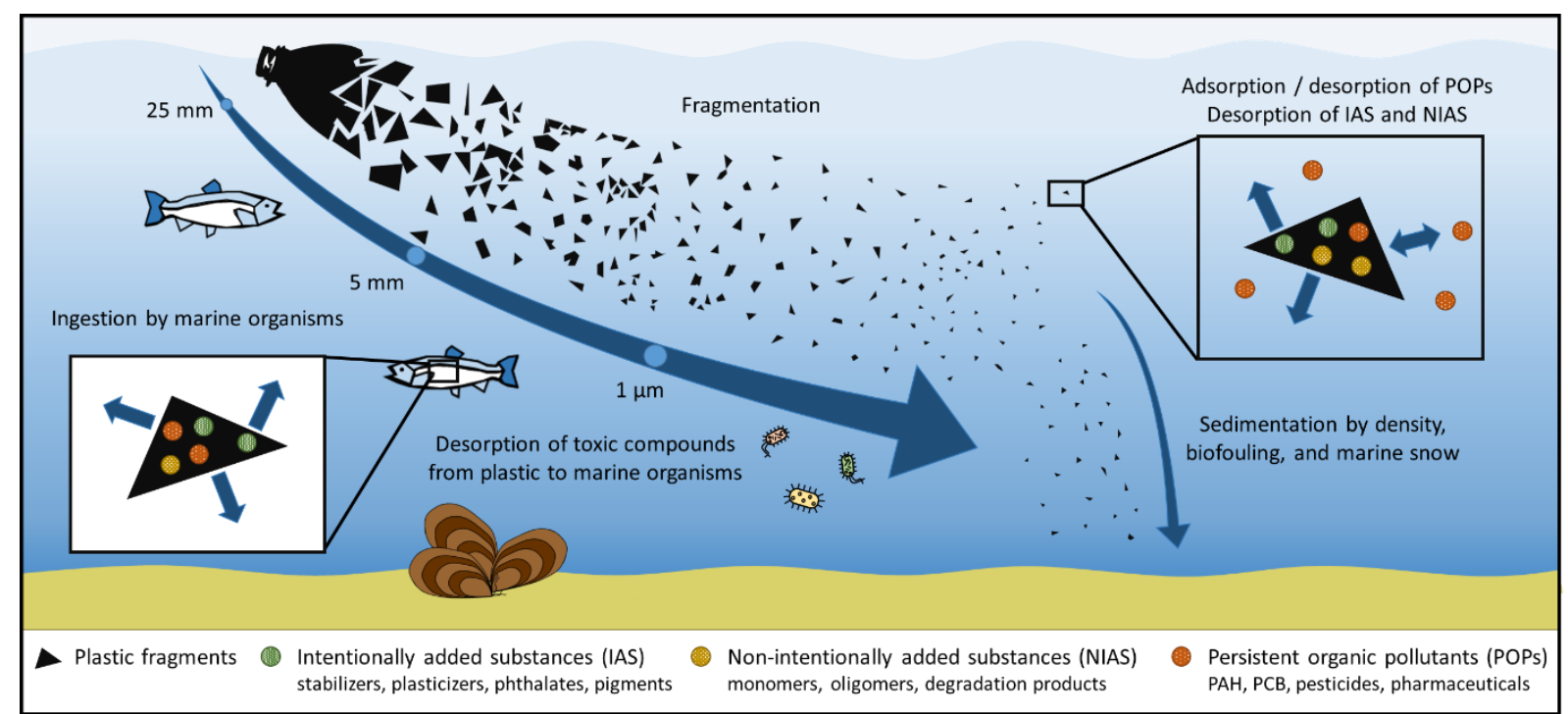

Figure 5: The effect of fragmentation and the sorption of toxic organic compounds onto plastic fragments on marine organisms. (double/colour)

\subsection{Consequences of fragmentation}

Fragmentation of marine plastic debris into micro and nano plastics requires not only UV weathering but also external mechanical forces caused by waves, wind etc. So far, plastic fragments were present in seawater, surface water, beaches, sediments and even in animals in all continents, oceans, and seas. Plastics abundance is up to 279 items $\mathrm{m}^{-3}$ in seawater samples and grows with time (Peng et al., 2020; Yu et al., 2020). Fragmentation is responsible of such trend and it can affect bioavailability and wildlife. In fact, as fragments size decreases, their ingestion by a wide diversity of organisms is favoured. For example, smaller particle size makes it available to lower trophic marine organisms such as mussels and zooplanktons (Auta et al., 2017; Barnes et al., 2009; Kalogerakis et al., 2017; Moore, 2008). Moreover, smaller particles were found to be more readily transfer through the different barriers of the organisms, thus reaching a wider range of organs (Kögel et al., 2020).

These physical impacts of plastic debris and micro and nanoplastics on marine organisms has been largely studied and recently reviewed (Haegerbaeumer et al., 2019; Jacquin et al., 2019; Kögel et al., 2020; Wright et al., 2013). As a consequence, this aspect will not be further developed here and, in the following, the impacts of the plastic photodegradation on the release and sorption of chemicals in/from the marine environment will be more specifically reviewed as well as the related toxicity aspects.

\subsection{Photodegradation products, additives and stabilizers leakage}

Additives and stabilizers are introduced intentionally in plastic's formulations to obtain certain desired 483 properties depending on the final application. These include antioxidant agents, anti-UV, plasticizers, phthalates, 
pigments, and flame retardants. These compounds can be released into the plastic's environment. On the other hand, NIAS such as monomers, oligomers with low molecular weight, degradation products, even heavy metals can also be released into the ocean. Studies showed that these compounds can be transported and leaked into the marine environment depending on their solubility in water, polarity, and affinity with the plastic. This is also controlled by external conditions such as temperature, water salinity, $\mathrm{pH}$ and water turbulence (Aminot et al., 2020; Cao et al., 2020; Eyheraguibel et al., 2018; Koelmans et al., 2014; Kwon et al., 2015; Nakashima et al., 2016; Suhrhoff and Scholz-Böttcher, 2016; Verma et al., 2016). The leakage rate and leaked compound's concentrations are higher for UV weathered samples compared with unaged pristine plastics (Bandow et al., 2017; Kedzierski et al., 2018; Luo et al., 2020). This can be due to the fact that UV-aged polymers contain a wider range of NIAS (c.f. section 2.2) and/or that changes in the polymers matrix (c.f. section 2.3) can modify the diffusion rate of compounds from the polymer to the water.

\subsection{Organic pollutants accumulation, transfer, and leakage}

\subsubsection{Sorption of organic pollutants}

Organic pollutants sorption consists of the adsorption of the pollutant to the plastic's surface and absorption of the pollutant to the material bulk. The sorption of organic pollutants in water depends mostly on the pollutant's nature and abundance, and the plastic's type, size, physical, and chemical properties (Allen et al., 2018; Fries and Zarfl, 2012; Hüffer and Hofmann, 2016; Lee et al., 2014; Li et al., 2018; Llorca et al., 2014; Razanajatovo et al., 2018). It depends also on external factors such as salinity, $\mathrm{pH}$, temperature, and water movement (Booij et al., 2003; Goedecke et al., 2017; Guo and Wang, 2019; Shen et al., 2018; Wang et al., 2015; F. Wang et al., 2018). It can also vary due to the cocktail effect, as there can be a competition in a mixture of organic pollutants for sorption sites (Bakir et al., 2012).

In recent years, there have been an increase of plastic debris sampling campaigns in the marine environment. This was usually followed by the characterization of plastics and the analysis of their chemical compositions. This was done mainly by solvent extraction followed by gas chromatography coupled with mass spectrometry analysis. Target contaminants consists mostly of polycyclic aromatic hydrocarbons (PAHs), polychlorobiphenyl (PCBs) and pesticides. Other sorbed contaminants can be pharmaceutical products and heavy metals.

According to polymer type, PE generally exhibits a greater sorption capacity to environmental pollutants than other plastic types (O'Connor et al., 2016; F. Wang et al., 2018). According to size, although decreasing particle 
size leads to higher specific surface area and thus higher sorption rate, the analysis of environmental samples showed that POPs concentrations did not vary significantly according to plastic's size (Chen et al., 2019; Endo and Koelmans, 2016; Goedecke et al., 2017).

As for POPs, PAHs showed higher concentrations in plastic debris than PCBs and pesticides (Antunes et al., 2013; Gauquie et al., 2015; Rios et al., 2010, 2007; Taniguchi et al., 2016; Van et al., 2012). The sum of 16 PAHs concentration can vary up to more than $119 \mu \mathrm{g} \mathrm{g}^{-1}$ depending on the plastic's type, the region and near contamination sources, while the concentration of PCBs can vary up to $4 \mu \mathrm{g} \mathrm{g}^{-1}$ (Gregory, 1978; Hong et al., 2018; Mai et al., 2018). For PAHs, the most abundant ones were two to four rings such as phenanthrene and chrysene. As for PCBs, the most abundant congeners varied according to regions and are mainly PCB 110, 187, 138, 101 and 170 (Bouhroum et al., 2019; Frias et al., 2010; Rios et al., 2010).

Concerning the spatial distribution, POPs concentrations near greater cities such as Porto and Sidney were higher than those observed near smaller and remote cities and islands such as Hawaiian Islands (Gómez et al., 2020; Heskett et al., 2012; Mizukawa et al., 2013; Ogata et al., 2009; Pozo et al., 2020; Taniguchi et al., 2016; Yeo et al., 2015; Zhang et al., 2015). Plus, POPs concentrations were significantly higher in plastic debris from coastal beaches than those from open ocean areas (Bouhroum et al., 2019; Chen et al., 2019; Hirai et al., 2011; Rios et al., 2007). POPs concentrations varied also according to sampling period (Karkanorachaki et al., 2018).

\subsubsection{Effect of aging on sorption}

Theoretically, weathering can enhance the adsorption capacity by increasing the surface specific area. On the other hand, the absorption capacity is reduced by polymer crystallinity growth. The formation of hydrophilic groups onto the plastic's surface can decline its affinity towards hydrophobic pollutants, but these hydrophilic groups (organic compounds, oligomers, polymer chain) in the natural environment are more likely to migrate to the surrounding water.

Giving the competing polymer changes and the complexity of factors in the marine environment, the sorption behaviour of POPs onto UV weathered plastics is still not fully understood. In order to investigate the sorption behaviour on weathered plastic, sorption laboratory tests are essential to understand the process even though they do not simulate exactly the complexity of the marine environment.

Recent laboratory studies showed that hydrophobic pollutants such as aliphatic compounds, fuel aromatics, and ethers sorbed less on UV aged PS than on pristine PS while no change in the sorption capacity was noted in 
the case of PP. Although the authors attributed the case of PS to the increase in surface polar functionalities such as carbonyl and hydroxyl groups, it can also be due to the polymer crystallinity growth (Hüffer et al., 2018; Müller et al., 2018). The sorption of hydrophilic organic compounds on UV weathered PS and PVC is favoured compared to pristine materials. This was explained by the change in interactions, as in pristine plastics the sorption mainly involved $\pi-\pi$ interactions while in UV weathered plastics it was controlled by electrostatic interactions and hydrogen bonding (Liu et al., 2019, 2020a).

In the case of environmental plastic debris, weathered plastic pellets were found to contain higher pollutants concentration than unaged pellets (Antunes et al., 2013; Frias et al., 2010; Karapanagioti and Klontza, 2008; Ogata et al., 2009). This can be attributed to the increase of the specific surface area of the weathered pellet and thus the favoured adsorption or to the changes in the polymer properties from weathering. But considering results from laboratory studies in this case, it is more likely attributed to the time spent in the ocean. In laboratory studies, both pristine and UV weathered plastics are exposed to organic pollutants for the same duration. Thus, the differences in sorption properties are attributed only to the weathering extent. While in marine plastic samples, weathered pellets which have been present for a longer time in the ocean hence their higher UV weathering degree. The longer time spent in the ocean would increase the concentration of POPs sorbed onto the pellet through absorption and the diffusion of POPs into the bulk of the plastic (Mato et al., 2001).

\subsubsection{Transfer and leakage}

Floating marine plastic debris can act as vectors for pollutants transfer in the environment. Polyolefins being lighter than water and the most abundant in the marine environment, can accumulate organic pollutants enriched in the sea surface microlayer. Then floating plastics can be easily transported by wind or wave action on water surface into remote areas and open ocean. Due to biofouling plastics can also sink via marine snow and transport the contaminant deeper into the water column (Hartmann et al., 2017; Kaiser et al., 2017; Kowalski et al., 2016; Mato et al., 2001; Sadri and Thompson, 2014; Teuten et al., 2007; Zarfl and Matthies, 2010; Zhang, 2017).

Highly contaminated plastic debris can transfer contaminants into seawater or biota (Bakir et al., 2014; León et al., 2018; Teuten et al., 2009, 2007). For example, high abundance of fibers was found to lead to higher contaminant transfer to sediments and cultured seafood (Z. Wang et al., 2018). Results of PCB content of the International Pellet Watch campaign was positively correlated with those from Mussel Watch campaign (Ogata et al., 2009). Thus, the transfer of POPs by plastic debris into the marine environment must be further investigated taking into account the influence of weathering extent and chemical content. 
The studies described here are limited to the effect of UV weathered plastic on the marine organisms. Bioavailability of plastic debris for filter feeders depends on its size, density, abundance, and colour (Wright et al., 2013).

As previously discussed, UV weathering affects the surface of the plastic and its chemical properties. This can change its affinity towards plastisphere communities, and increase the development of biofilm that can be linked to the formation of the photodegradation products possibly utilized by microorganisms (Rummel et al., 2017; Zettler et al., 2013). Developing biofilm can affect the affinity of colonized plastic particle towards marine organisms, thus affecting the ingestion of the particle. For example, UV weathering promotes biofilm development that promotes its ingestion by zooplankton but decreases its ingestion by marine larva (Kaposi et al., 2014; Vroom et al., 2017).

UV weathering can also contribute to the toxicity of plastic debris on marine organisms due to the possible leakage of NIAS and / or IAS (potential estrogenic and endocrine disruptors) in seawater (Chen et al., 2019; Coffin et al., 2018; Kedzierski et al., 2018). The leakage can be utilized by marine bacteria, but it can also inhibit microbial activity (Zhu et al., 2020). The leakage can also inhibit cell growth and photosynthesis of marine algae (Luo et al., 2020). Another study on brown mussels showed that leakage from aged beach pellets is more toxic than that of pristine pellets (Gandara e Silva et al., 2016).

\section{Conclusion}

This work reviews the mechanism of plastics UV weathering and its characteristics, compares plastic's characteristics according to the natural/laboratory UV weathering medium, and provides an overview on the environmental impacts of UV weathered plastics. The fate of plastics depends on their initial characteristics, their weatherability and the weathering conditions. Even though several spectroscopic and microscopic techniques are used to characterize marine plastic debris, there are still limitations in the determination of the weathering extent. The path taken by the plastic and the time spent in the marine environment are difficult to be assessed as photodegradation products leakage and plastic fragmentation can occur. More research and models should be employed in order to determine the exact weathering extent of marine plastic debris. 
UV weathering can lead to fragmentation and the formation of smaller plastic particles down to the nano scale.

Little is still known on the nano fraction and its impact on the environment. Thus, it is important to conduct more research concerning the formation and impact of this nano fraction.

The impact of UV weathered plastics was briefly discussed in term of additives and photodegradation products leakage, interaction with POPs, and its effect on marine organisms. Plastic debris, according to their weathering extent and / or time spent in the marine environment, can accumulate POPs that can eventually be transferred with the plastic to remote unpolluted areas. These weathered plastics can also release photodegradation products, NIAS and IAS into the water that can be toxic to certain marine organisms. Nonetheless, some of the photodegradation products can be utilized by other marine microorganisms and induce their growth. Thus, the toxicological effect of the cocktail plastic - POPs - photodegradation products depends mostly on the organisms studied.

Actually, there are over than $150 \mathrm{Mt}$ of plastic debris in the ocean, without significant intervention, by 2050 there could be more plastic than fish in the sea (Kosior and Mitchell, 2020). Thus, it is important to raise awareness among people and reinforce global legislation concerning the impact of plastic waste on the marine environment.

\section{References}

Agboola, O., Sadiku, R., Mokrani, T., Amer, I., Imoru, O., 2017. Polyolefins and the environment, in: Polyolefin Fibres. Elsevier, pp. 89-133. https://doi.org/10.1016/B978-0-08-101132-4.00004-7

Allen, N.S., Fatinikun, K.O., 1981. Destruction of carbonyl and hydroperoxide groups in oxidised polypropylene: Effect on photo-oxidation. Polym. Degrad. Stab. 3, 327-332. https://doi.org/10.1016/01413910(81)90038-0

Allen, N.S., MacKellar, J.F., 1980. Photochemistry of dyed and pigmented polymers. Applied Science Publishers, London.

Allen, T., S, F., J, D., C, C., B, P., 2018. Variations in Sorption of Organochlorine Pesticides and PCBs across Six Different Plastic Polymers. J. Environ. Toxicol. studies. 2. https://doi.org/10.16966/2576-6430.109

Al-Salem, S.M., 2009. Influence of natural and accelerated weathering on various formulations of linear low density polyethylene (LLDPE) films. Materials \& Design 30, 1729-1736. https://doi.org/10.1016/j.matdes.2008.07.049

Al-Salem, S.M., Al-Nasser, A.Y., Al-Wadi, M.H., Sultan, H.H., Karam, H.J., Al-Dhafeeri, A.T., Al-Foudaree, M., Rasheed, Z., 2019. Mechanical profiling of commercial grade biodegradable plastic films post exposure to natural and accelerated weathering. Presented at the MATERIALS CHARACTERISATION 2019, Lisbon, Portugal, pp. 229-242. https://doi.org/10.2495/MC190221

Aminot, Y., Lanctôt, C., Bednarz, V., Robson, W.J., Taylor, A., Ferrier-Pagès, C., Metian, M., Tolosa, I., 2020. Leaching of flame-retardants from polystyrene debris: Bioaccumulation and potential effects on coral. Mar. Pollut. Bull. 151, 110862. https://doi.org/10.1016/j.marpolbul.2019.110862

Andrade, J., Fernández-González, V., López-Mahía, P., Muniategui, S., 2019. A low-cost system to simulate environmental microplastic weathering. Mar. Pollut. Bull. 149, 110663. https://doi.org/10.1016/j.marpolbul.2019.110663

Andrady, A.L., 2017. The plastic in microplastics: A review. Mar. Pollut. Bull. 119, 12-22. https://doi.org/10.1016/j.marpolbul.2017.01.082

Andrady, A.L., 2011. Microplastics in the marine environment. Mar. Pollut. Bull. 62, 1596-1605. https://doi.org/10.1016/j.marpolbul.2011.05.030

Andrady, A.L., 1989. Environmental degradation of plastics under land and marine exposure conditions., in: Proceedings of the Second International Conference on Marine Debris. p. 22. 
Andrady, A.L., Pandey, K.K., Heikkilä, A.M., 2019. Interactive effects of solar UV radiation and climate change on material damage. Photochem. Photobiol. Sci. 18, 804-825. https://doi.org/10.1039/C8PP90065E

Andrady, A.L., Pegram, J.E., 1991. Weathering of polystyrene foam on exposure in air and in seawater. J. Appl. Polym. Sci. 42, 1589-1596. https://doi.org/10.1002/app.1991.070420612

Andrady, A.L., Pegram, J.E., Song, Y., 1993. Studies on enhanced degradable plastics. II. Weathering of enhanced photodegradable polyethylenes under marine and freshwater floating exposure. J Environ Polym Degr 1, 117-126. https://doi.org/10.1007/BF01418205

Antunes, J.C., Frias, J.G.L., Micaelo, A.C., Sobral, P., 2013. Resin pellets from beaches of the Portuguese coast and adsorbed persistent organic pollutants. Estuarine, Coastal and Shelf Science 130, 62-69. https://doi.org/10.1016/j.ecss.2013.06.016

Audouin, L., Girois, S., Achimsky, L., Verdu, J., 1998. Effect of temperature on the photooxidation of polypropylene films. Polymer Degradation and Stability 60, 137-143. https://doi.org/10.1016/S01413910(97)00042-6

Auta, H.S., Emenike, C.U., Fauziah, S.H., 2017. Distribution and importance of microplastics in the marine environment: A review of the sources, fate, effects, and potential solutions. Environ. Int. 102, 165-176. https://doi.org/10.1016/j.envint.2017.02.013

Avenel, C., Gardette, J.-L., Therias, S., Disdier, A., Raccurt, O., 2017. Accelerated aging test of solar mirrors: Comparison of different UV chambers. Presented at the SOLARPACES 2016: International Conference on Concentrating Solar Power and Chemical Energy Systems, Abu Dhabi, United Arab Emirates, p. 130001. https://doi.org/10.1063/1.4984495

Avenel, C., Raccurt, O., Gardette, J.-L., Therias, S., 2018. Review of accelerated ageing test modelling and its application to solar mirrors. Solar Energy Materials and Solar Cells 186, $29-41$. https://doi.org/10.1016/j.solmat.2018.06.024

Bakir, A., Rowland, S.J., Thompson, R.C., 2014. Transport of persistent organic pollutants by microplastics in estuarine conditions. Estuarine, Coastal and Shelf Science 140, 14-21. https://doi.org/10.1016/j.ecss.2014.01.004

Bakir, A., Rowland, S.J., Thompson, R.C., 2012. Competitive sorption of persistent organic pollutants onto microplastics in the marine environment. Mar. Pollut. Bull. 64, 2782-2789. https://doi.org/10.1016/j.marpolbul.2012.09.010

Bandow, N., Will, V., Wachtendorf, V., Simon, F.-G., 2017. Contaminant release from aged microplastic. Environ. Chem. 14, 394. https://doi.org/10.1071/EN17064

Barnes, D.K.A., Galgani, F., Thompson, R.C., Barlaz, M., 2009. Accumulation and fragmentation of plastic debris in global environments. Phil. Trans. R. Soc. B 364, 1985-1998. https://doi.org/10.1098/rstb.2008.0205

Beltrán-Sanahuja, A., Casado-Coy, N., Simó-Cabrera, L., Sanz-Lázaro, C., 2020. Monitoring polymer degradation under different conditions in the marine environment. Environ. Pollut. 259, 113836. https://doi.org/10.1016/j.envpol.2019.113836

Biber, N.F.A., Foggo, A., Thompson, R.C., 2019. Characterising the deterioration of different plastics in air and seawater. Mar. Pollut. Bull. 141, 595-602. https://doi.org/10.1016/j.marpolbul.2019.02.068

Billingham, N.C., 1993. The physical chemistry of polymer oxidation and stabilization., in: Atmospheric Oxidation and Antioxidants. Elsevier, Amsterdam, pp. 219-77.

Bolland, J.L., 1949. Kinetics of olefin oxidation. Quarterly Reviews, Chemical Society. 21.

Booij, K., Hofmans, H.E., Fischer, C.V., Van Weerlee, E.M., 2003. Temperature-Dependent Uptake Rates of Nonpolar Organic Compounds by Semipermeable Membrane Devices and Low-Density Polyethylene Membranes. Environ. Sci. Technol. 37, 361-366. https://doi.org/10.1021/es025739i

Bouhroum, R., Boulkamh, A., Asia, L., Lebarillier, S., Halle, A.T., Syakti, A.D., Doumenq, P., Malleret, L., WongWah-chung, P., 2019. Concentrations and fingerprints of PAHs and PCBs adsorbed onto marine plastic debris from the Indonesian Cilacap coast and theNorth Atlantic gyre. Regional Studies in Marine Science 29, 100611. https://doi.org/10.1016/j.rsma.2019.100611

Brandon, J., Goldstein, M., Ohman, M.D., 2016. Long-term aging and degradation of microplastic particles: Comparing in situ oceanic and experimental weathering patterns. Mar. Pollut. Bull. 110, 299-308. https://doi.org/10.1016/j.marpolbul.2016.06.048

Brydson, J.A., 1999. Plastics materials, 7th ed. ed. Butterworth-Heinemann, Oxford ; Boston.

Cai, L., Wang, J., Peng, J., Wu, Z., Tan, X., 2018. Observation of the degradation of three types of plastic pellets exposed to UV irradiation in three different environments. Sci. Total Environ. 628-629, 740-747. https://doi.org/10.1016/j.scitotenv.2018.02.079

Cao, X., Wang, L., Zhang, Y., Li, Y., Zhu, C., Zheng, X., Sun, Y., Li, D., Mo, L., Mai, B., 2020. Occurrence of organic pollutants in plastics on beach: Stranded foams can be sources of pollutants in islands. Sci. Total Environ. 707, 136119. https://doi.org/10.1016/j.scitotenv.2019.136119

Ceccarini, A., Corti, A., Erba, F., Modugno, F., La Nasa, J., Bianchi, S., Castelvetro, V., 2018. The Hidden Microplastics: New Insights and Figures from the Thorough Separation and Characterization of 
Microplastics and of Their Degradation Byproducts in Coastal Sediments. Environ. Sci. Technol. 52, 5634-5643. https://doi.org/10.1021/acs.est.8b01487

Chabert, B., Gardette, J.L., Lachenal, G., Stevenson, I., 1997. Applications of FT-Raman and FT-IR Microspectroscopy in the Near Infrared to Polymer Analysis, in: Mink, J., Keresztury, G., Kellner, R. (Eds.), Progress in Fourier Transform Spectroscopy. Springer Vienna, Vienna, pp. 399-402. https://doi.org/10.1007/978-3-7091-6840-0_93

Chen, Q., Zhang, H., Allgeier, A., Zhou, Q., Ouellet, J.D., Crawford, S.E., Luo, Y., Yang, Y., Shi, H., Hollert, H., 2019. Marine microplastics bound dioxin-like chemicals: Model explanation and risk assessment. Journal of Hazardous Materials 364, 82-90. https://doi.org/10.1016/j.jhazmat.2018.10.032

Chubarenko, I., Efimova, I., Bagaeva, M., Bagaev, A., Isachenko, I., 2020. On mechanical fragmentation of singleuse plastics in the sea swash zone with different types of bottom sediments: Insights from laboratory experiments. Mar. Pollut. Bull. 150, 110726. https://doi.org/10.1016/j.marpolbul.2019.110726

Clunie, W.F., Hendricks, D.W., 1996. Refuse Pollution of Seas and Oceans 11.

Coffin, S., Dudley, S., Taylor, A., Wolf, D., Wang, J., Lee, I., Schlenk, D., 2018. Comparisons of analytical chemistry and biological activities of extracts from North Pacific gyre plastics with UV-treated and untreated plastics using in vitro and in vivo models. Environment International 121, 942-954. https://doi.org/10.1016/j.envint.2018.10.012

Cooper, D.A., Corcoran, P.L., 2010. Effects of mechanical and chemical processes on the degradation of plastic beach debris on the island of Kauai, Hawaii. Mar. Pollut. Bull. 60, 650-654. https://doi.org/10.1016/j.marpolbul.2009.12.026

Copinet, A., Bertrand, C., Govindin, S., Coma, V., Couturier, Y., 2004. Effects of ultraviolet light (315 nm), temperature and relative humidity on the degradation of polylactic acid plastic films. Chemosphere 55, 763-773. https://doi.org/10.1016/j.chemosphere.2003.11.038

Corami, F., Rosso, B., Bravo, B., Gambaro, A., Barbante, C., 2020. A novel method for purification, quantitative analysis and characterization of microplastic fibers using Micro-FTIR. Chemosphere 238, 124564. https://doi.org/10.1016/j.chemosphere.2019.124564

Corcoran, P.L., Biesinger, M.C., Grifi, M., 2009. Plastics and beaches: A degrading relationship. Mar. Pollut. Bull. 58, 80-84. https://doi.org/10.1016/j.marpolbul.2008.08.022

Efimova, I., Bagaeva, M., Bagaev, A., Kileso, A., Chubarenko, I.P., 2018. Secondary Microplastics Generation in the Sea Swash Zone With Coarse Bottom Sediments: Laboratory Experiments. Front. Mar. Sci. 5, 313. https://doi.org/10.3389/fmars.2018.00313

Endo, S., Koelmans, A.A., 2016. Sorption of Hydrophobic Organic Compounds to Plastics in the Marine Environment: Equilibrium, in: Takada, H., Karapanagioti, H.K. (Eds.), Hazardous Chemicals Associated with Plastics in the Marine Environment. Springer International Publishing, Cham, pp. 185-204. https://doi.org/10.1007/698_2016_11

Eriksen, M., Lebreton, L.C.M., Carson, H.S., Thiel, M., Moore, C.J., Borerro, J.C., Galgani, F., Ryan, P.G., Reisser, J., 2014. Plastic Pollution in the World's Oceans: More than 5 Trillion Plastic Pieces Weighing over 250,000 Tons Afloat at Sea. PLoS ONE 9, e111913. https://doi.org/10.1371/journal.pone.0111913

Erni-Cassola, G., Zadjelovic, V., Gibson, M.I., Christie-Oleza, J.A., 2019. Distribution of plastic polymer types in the marine environment; A meta-analysis. Journal of Hazardous Materials 369, 691-698. https://doi.org/10.1016/j.jhazmat.2019.02.067

Escobar, L.A., Meeker, W.Q., 2006. A Review of Accelerated Test Models. Statist. Sci. 21. https://doi.org/10.1214/088342306000000321

Espí, E., Salmerón, A., Fontecha, A., García, Y., Real, A.I., 2007. The effect of different variables on the accelerated and natural weathering of agricultural films. Polym. Degrad. Stab. 92, 2150-2154. https://doi.org/10.1016/j.polymdegradstab.2006.12.016

Eyheraguibel, B., Leremboure, M., Traikia, M., Sancelme, M., Bonhomme, S., Fromageot, D., Lemaire, J., Lacoste, J., Delort, A.M., 2018. Environmental scenarii for the degradation of oxo-polymers. Chemosphere 198, 182-190. https://doi.org/10.1016/j.chemosphere.2018.01.153

Fairbrother, A., Hsueh, H.-C., Kim, J.H., Jacobs, D., Perry, L., Goodwin, D., White, C., Watson, S., Sung, L.-P., 2019. Temperature and light intensity effects on photodegradation of high-density polyethylene. Polym. Degrad. Stab. 165, 153-160. https://doi.org/10.1016/j.polymdegradstab.2019.05.002

Fechine, G.J.M., Rabello, M.S., Souto-Maior, R.M., 2002. The effect of ultraviolet stabilizers on the photodegradation of poly(ethylene terephthalate). Polym. Degrad. Stab. 75, 153-159. https://doi.org/10.1016/S0141-3910(01)00214-2

Feldman, D., 2002. Polymer Weathering: Photo-Oxidation. J. Polym. Environ. 10, 163-173.

Feldman, D., 1981. Natural and accelerated weathering of some polyblends. J. Appl. Polym. Sci. 26, 3493-3501. https://doi.org/10.1002/app.1981.070261028

Filella, M., 2015. Questions of size and numbers in environmental research on microplastics: methodological and conceptual aspects. Environ. Chem. 12, 527. https://doi.org/10.1071/EN15012 
Fischer, M., Scholz-Böttcher, B.M., 2017. Simultaneous Trace Identification and Quantification of Common Types of Microplastics in Environmental Samples by Pyrolysis-Gas Chromatography-Mass Spectrometry. Environ. Sci. Technol. 51, 5052-5060. https://doi.org/10.1021/acs.est.6b06362

Fotopoulou, K.N., Karapanagioti, H.K., 2017. Degradation of Various Plastics in the Environment, in: Takada, H., Karapanagioti, H.K. (Eds.), Hazardous Chemicals Associated with Plastics in the Marine Environment, The Handbook of Environmental Chemistry. Springer International Publishing, Cham, pp. 71-92. https://doi.org/10.1007/698_2017_11

Fred-Ahmadu, O.H., Bhagwat, G., Oluyoye, I., Benson, N.U., Ayejuyo, O.O., Palanisami, T., 2020. Interaction of chemical contaminants with microplastics: Principles and perspectives. Sci. Total Environ. 706, 135978. https://doi.org/10.1016/j.scitotenv.2019.135978

Frias, J.P.G.L., Sobral, P., Ferreira, A.M., 2010. Organic pollutants in microplastics from two beaches of the Portuguese coast. Mar. Pollut. Bull. 60, 1988-1992. https://doi.org/10.1016/j.marpolbul.2010.07.030

Fries, E., Dekiff, J.H., Willmeyer, J., Nuelle, M.-T., Ebert, M., Remy, D., 2013. Identification of polymer types and additives in marine microplastic particles using pyrolysis-GC/MS and scanning electron microscopy. Environ. Sci.: Processes Impacts 15, 1949. https://doi.org/10.1039/c3em00214d

Fries, E., Zarfl, C., 2012. Sorption of polycyclic aromatic hydrocarbons (PAHs) to low and high density polyethylene (PE). Environ. Sci. Pollut. Res. 19, 1296-1304. https://doi.org/10.1007/s11356-011-06555

Gallo, F., Fossi, C., Weber, R., Santillo, D., Sousa, J., Ingram, I., Nadal, A., Romano, D., 2018. Marine litter plastics and microplastics and their toxic chemicals components: the need for urgent preventive measures. Environ Sci Eur 30, 13. https://doi.org/10.1186/s12302-018-0139-z

Gandara e Silva, P.P., Nobre, C.R., Resaffe, P., Pereira, C.D.S., Gusmão, F., 2016. Leachate from microplastics impairs larval development in brown mussels. Water Res. 106, 364-370. https://doi.org/10.1016/j.watres.2016.10.016

Gardette, J.L., 2000. Fundamental and technical aspects of the photoageing of polymers. Handbbok of Polymer Degradation, in: Handbook of Polymer Degradation. CRC Press, pp. 671-698.

Gardette, J.-L., 1993. MicroFTIR spectroscopic profiling of aged polymer films Spectroscopy Europe. 5, $28-32$.

Gardette, M., Perthue, A., Gardette, J.-L., Janecska, T., Földes, E., Pukánszky, B., Therias, S., 2013. Photo- and thermal-oxidation of polyethylene: Comparison of mechanisms and influence of unsaturation content. Polym. Degrad. Stab. 98, 2383-2390. https://doi.org/10.1016/j.polymdegradstab.2013.07.017

Gauquie, J., Devriese, L., Robbens, J., De Witte, B., 2015. A qualitative screening and quantitative measurement of organic contaminants on different types of marine plastic debris. Chemosphere 138, 348-356. https://doi.org/10.1016/j.chemosphere.2015.06.029

Gewert, B., Plassmann, M.M., MacLeod, M., 2015. Pathways for degradation of plastic polymers floating in the marine environment. Environ. Sci. Process Impacts. 17, 1513-1521. https://doi.org/10.1039/C5EM00207A

Geyer, R., 2020. Production, use, and fate of synthetic polymers, in: Plastic Waste and Recycling. Elsevier, pp. 13-32. https://doi.org/10.1016/B978-0-12-817880-5.00002-5

Gigault, J., Halle, A. ter, Baudrimont, M., Pascal, P.-Y., Gauffre, F., Phi, T.-L., El Hadri, H., Grassl, B., Reynaud, S., 2018. Current opinion: What is a nanoplastic? Environ. Pollut. 235, 1030-1034. https://doi.org/10.1016/j.envpol.2018.01.024

Gigault, J., Pedrono, B., Maxit, B., Ter Halle, A., 2016. Marine plastic litter: the unanalyzed nano-fraction. Environ. Sci.: Nano 3, 346-350. https://doi.org/10.1039/C6EN00008H

Gijsman, P., 2017. 18 - Polymer Stabilization. Applied Plastics Engineering Handbook 27.

Gijsman, P., Meijers, G., Vitarelli, G., 1999. Comparison of the UV-degradation chemistry of polypropylene, polyethylene, polyamide 6 and polybutylene terephthalate. Polym. Degrad. Stab. 65, 433-441. https://doi.org/10.1016/S0141-3910(99)00033-6

Girão, A.V., Caputo, G., Ferro, M.C., 2017. Application of Scanning Electron Microscopy-Energy Dispersive XRay Spectroscopy (SEM-EDS), in: Comprehensive Analytical Chemistry. Elsevier, pp. 153-168. https://doi.org/10.1016/bs.coac.2016.10.002

Gniadek, M., Dąbrowska, A., 2019. The marine nano- and microplastics characterisation by SEM-EDX: The potential of the method in comparison with various physical and chemical approaches. Mar. Pollut. Bull. 148, 210-216. https://doi.org/10.1016/j.marpolbul.2019.07.067

Goedecke, C., Stollin, U.M., Hering, S., Richter, J., Piechotta, C., Paul, A., Braun, U., 2017. A First Pilot Study on the Sorption of Environmental Pollutants on Various Microplastic Materials. Journal of Environmental Analytical Chemistry 04. https://doi.org/10.4172/2380-2391.1000191

Gómez, V., Pozo, K., Nuñez, D., Přibylová, P., Audy, O., Baini, M., Fossi, M.C., Klánová, J., 2020. Marine plastic debris in Central Chile: Characterization and abundance of macroplastics and burden of persistent organic pollutants (POPs). Mar. Pollut. Bull. 152, 110881. https://doi.org/10.1016/j.marpolbul.2019.110881 
Gregory, M.R., 1978. Accumulation and distribution of virgin plastic granules on New Zealand beaches. New Zealand Journal of Marine and Freshwater Research 12, 399-414. https://doi.org/10.1080/00288330.1978.9515768

Gugumus, F., 1995. The performance of light stabilizers in accelerated and natural weathering. Polym. Degrad. Stab. 50, 101-116. https://doi.org/10.1016/0141-3910(95)00134-8

Guo, X., Wang, J., 2019. Sorption of antibiotics onto aged microplastics in freshwater and seawater. Mar. Pollut. Bull. 149, 110511. https://doi.org/10.1016/j.marpolbul.2019.110511

Haegerbaeumer, A., Mueller, M.-T., Fueser, H., Traunspurger, W., 2019. Impacts of Micro- and Nano-Sized Plastic Particles on Benthic Invertebrates: A Literature Review and Gap Analysis. Front. Environ. Sci. 7, 17. https://doi.org/10.3389/fenvs.2019.00017

Hartmann, N.B., Rist, S., Bodin, J., Jensen, L.H., Schmidt, S.N., Mayer, P., Meibom, A., Baun, A., 2017. Microplastics as vectors for environmental contaminants: Exploring sorption, desorption, and transfer to biota: Microplastics as Contaminant Vectors: Exploring the Processes. Integrated Environmental Assessment and Management 13, 488-493. https://doi.org/10.1002/ieam.1904

Hermabessiere, L., Himber, C., Boricaud, B., Kazour, M., Amara, R., Cassone, A.-L., Laurentie, M., Paul-Pont, I., Soudant, P., Dehaut, A., Duflos, G., 2018. Optimization, performance, and application of a pyrolysisGC/MS method for the identification of microplastics. Anal. Bioanal. Chem. 410, 6663-6676. https://doi.org/10.1007/s00216-018-1279-0

Heskett, M., Takada, H., Yamashita, R., Yuyama, M., Ito, M., Geok, Y.B., Ogata, Y., Kwan, C., Heckhausen, A., Taylor, H., Powell, T., Morishige, C., Young, D., Patterson, H., Robertson, B., Bailey, E., Mermoz, J., 2012. Measurement of persistent organic pollutants (POPs) in plastic resin pellets from remote islands: Toward establishment of background concentrations for International Pellet Watch. Mar. Pollut. Bull. 64, 445-448. https://doi.org/10.1016/j.marpolbul.2011.11.004

Hidalgo-Ruz, V., Gutow, L., Thompson, R.C., Thiel, M., 2012. Microplastics in the Marine Environment: A Review of the Methods Used for Identification and Quantification. Environ. Sci. Technol. 46, 3060-3075. https://doi.org/10.1021/es2031505

Hiejima, Y., Kida, T., Takeda, K., Igarashi, T., Nitta, K., 2018. Microscopic structural changes during photodegradation of low-density polyethylene detected by Raman spectroscopy. Polym. Degrad. Stab. 150, 67-72. https://doi.org/10.1016/j.polymdegradstab.2018.02.010

Hildebrandt, L., Gareb, F.E., Zimmermann, T., Klein, O., Emeis, K.-C., 2020. Fast, Automated Microplastics Analysis Using Laser Direct Chemical Imaging. Application Note. Environ. Water Anal. 8.

Hirai, H., Takada, H., Ogata, Y., Yamashita, R., Mizukawa, K., Saha, M., Kwan, C., Moore, C., Gray, H., Laursen, D., Zettler, E.R., Farrington, J.W., Reddy, C.M., Peacock, E.E., Ward, M.W., 2011. Organic micropollutants in marine plastics debris from the open ocean and remote and urban beaches. Mar. Pollut. Bull. 62, 1683-1692. https://doi.org/10.1016/j.marpolbul.2011.06.004

Hofman, R., 1995. The changing focus of marine mammal conservation. Trends in Ecology \& Evolution 10, 462465. https://doi.org/10.1016/S0169-5347(00)89184-3

Hong, S.H., Shim, W.J., Jang, M., 2018. Chemicals Associated With Marine Plastic Debris and Microplastics: Analyses and Contaminant Levels, in: Microplastic Contamination in Aquatic Environments. Elsevier, pp. 271-315. https://doi.org/10.1016/B978-0-12-813747-5.00009-6

Hüffer, T., Hofmann, T., 2016. Sorption of non-polar organic compounds by micro-sized plastic particles in aqueous solution. Environ. Pollut. 214, 194-201. https://doi.org/10.1016/j.envpol.2016.04.018

Hüffer, T., Weniger, A.-K., Hofmann, T., 2018. Sorption of organic compounds by aged polystyrene microplastic particles. Environ. Pollut. 236, 218-225. https://doi.org/10.1016/j.envpol.2018.01.022

Hurley, R., Horton, A., Lusher, A., Nizzetto, L., 2020. Plastic waste in the terrestrial environment, in: Plastic Waste and Recycling. Elsevier, pp. 163-193. https://doi.org/10.1016/B978-0-12-817880-5.00007-4

Industrievereinigung Chemiefaser, 2020. Die Chemiefaserindustrie in der Bundesrepublik Deutschland.

Ioakeimidis, C., Fotopoulou, K.N., Karapanagioti, H.K., Geraga, M., Zeri, C., Papathanassiou, E., Galgani, F., Papatheodorou, G., 2016. The degradation potential of PET bottles in the marine environment: An ATRFTIR based approach. Sci Rep 6, 23501. https://doi.org/10.1038/srep23501

Jacquin, J., Cheng, J., Odobel, C., Pandin, C., Conan, P., Pujo-Pay, M., Barbe, V., Meistertzheim, A.-L., Ghiglione, J.-F., 2019. Microbial Ecotoxicology of Marine Plastic Debris: A Review on Colonization and Biodegradation by the "Plastisphere." Front. Microbiol. 10, 865. https://doi.org/10.3389/fmicb.2019.00865

Jambeck, J.R., Geyer, R., Wilcox, C., Siegler, T.R., Perryman, M., Andrady, A., Narayan, R., Law, K.L., 2015. Plastic waste inputs from land into the ocean. Mar. Pollut. 347, 768-771.

Jouan, X., Gardette, J.-L., 1987. Development of a micro (FTIR) spectrometric method for characterisation of heterogeneities in polymer films. Polymer Communications 28, 329-331. 
Julienne, F., Delorme, N., Lagarde, F., 2019. From macroplastics to microplastics: Role of water in the fragmentation of $\quad$ polyethylene. https://doi.org/10.1016/j.chemosphere.2019.124409

Jung, M.R., Horgen, F.D., Orski, S.V., Rodriguez C., V., Beers, K.L., Balazs, G.H., Jones, T.T., Work, T.M., Brignac, K.C., Royer, S.-J., Hyrenbach, K.D., Jensen, B.A., Lynch, J.M., 2018. Validation of ATR FTIR to identify polymers of plastic marine debris, including those ingested by marine organisms. Mar. Pollut. Bull. 127, 704-716. https://doi.org/10.1016/j.marpolbul.2017.12.061

Kaiser, D., Kowalski, N., Waniek, J.J., 2017. Effects of biofouling on the sinking behavior of microplastics. Environ. Res. Lett. 12, 124003. https://doi.org/10.1088/1748-9326/aa8e8b

Kalogerakis, N., Karkanorachaki, K., Kalogerakis, G.C., Triantafyllidi, E.I., Gotsis, A.D., Partsinevelos, P., Fava, F., 2017. Microplastics Generation: Onset of Fragmentation of Polyethylene Films in Marine Environment Mesocosms. Front. Mar. Sci. 4. https://doi.org/10.3389/fmars.2017.00084

Kaposi, K.L., Mos, B., Kelaher, B.P., Dworjanyn, S.A., 2014. Ingestion of Microplastic Has Limited Impact on a Marine Larva. Environ. Sci. Technol. 48, 1638-1645. https://doi.org/10.1021/es404295e

Karapanagioti, H.K., Klontza, I., 2008. Testing phenanthrene distribution properties of virgin plastic pellets and plastic eroded pellets found on Lesvos island beaches (Greece). Marine Environmental Research 65, 283290. https://doi.org/10.1016/j.marenvres.2007.11.005

Karkanorachaki, K., Kiparissis, S., Kalogerakis, G.C., Yiantzi, E., Psillakis, E., Kalogerakis, N., 2018. Plastic pellets, meso- and microplastics on the coastline of Northern Crete: Distribution and organic pollution. Mar. Pollut. Bull. 133, 578-589. https://doi.org/10.1016/j.marpolbul.2018.06.011

Kedzierski, M., D’Almeida, M., Magueresse, A., Le Grand, A., Duval, H., César, G., Sire, O., Bruzaud, S., Le Tilly, V., 2018. Threat of plastic ageing in marine environment. Adsorption/desorption of micropollutants. Mar. Pollut. Bull. 127, 684-694. https://doi.org/10.1016/j.marpolbul.2017.12.059

Kockott, D., 1989. Natural and artificial weathering of polymers. Polym. Degrad. Stab. 25, 181-208. https://doi.org/10.1016/S0141-3910(89)81007-9

Koelmans, A.A., Besseling, E., Foekema, E.M., 2014. Leaching of plastic additives to marine organisms. Environ. Pollut. 187, 49-54. https://doi.org/10.1016/j.envpol.2013.12.013

Kögel, T., Bjorøy, Ø., Toto, B., Bienfait, A.M., Sanden, M., 2020. Micro- and nanoplastic toxicity on aquatic life: Determining factors. Sci. Total Environ. 16.

Kosior, E., Mitchell, J., 2020. Current industry position on plastic production and recycling, in: Plastic Waste and Recycling. Elsevier, pp. 133-162. https://doi.org/10.1016/B978-0-12-817880-5.00006-2

Kowalski, N., Reichardt, A.M., Waniek, J.J., 2016. Sinking rates of microplastics and potential implications of their alteration by physical, biological, and chemical factors. Mar. Pollut. Bull. 109, 310-319. https://doi.org/10.1016/j.marpolbul.2016.05.064

Kwon, B.G., Koizumi, K., Chung, S.-Y., Kodera, Y., Kim, J.-O., Saido, K., 2015. Global styrene oligomers monitoring as new chemical contamination from polystyrene plastic marine pollution. Journal of Hazardous Materials 300, 359-367. https://doi.org/10.1016/j.jhazmat.2015.07.039

Lambert, S., Wagner, M., 2016a. Formation of microscopic particles during the degradation of different polymers. Chemosphere 161, 510-517. https://doi.org/10.1016/j.chemosphere.2016.07.042

Lambert, S., Wagner, M., 2016b. Characterisation of nanoplastics during the degradation of polystyrene. Chemosphere 145, 265-268. https://doi.org/10.1016/j.chemosphere.2015.11.078

Larché, J.F., Bussière, P.O., Gardette, J.L., 2011. Characterisation of accelerated ageing devices for prediction of the service life of acrylic-melamine/urethane thermosets. Polym. Degrad. Stab. 96, 1530-1536. https://doi.org/10.1016/j.polymdegradstab.2011.04.013

Larché, J.-F., Bussière, P.-O., Thérias, S., Gardette, J.-L., 2012. Photooxidation of polymers: Relating material properties to chemical changes. Polym. Degrad. Stab. 97, 25-34. https://doi.org/10.1016/j.polymdegradstab.2011.10.020

Le, D.Q., Takada, H., Yamashita, R., Mizukawa, K., Hosoda, J., Tuyet, D.A., 2016. Temporal and spatial changes in persistent organic pollutants in Vietnamese coastal waters detected from plastic resin pellets. Mar. Pollut. Bull. 109, 320-324. https://doi.org/10.1016/j.marpolbul.2016.05.063

Lebreton, L.C.M., van der Zwet, J., Damsteeg, J.-W., Slat, B., Andrady, A., Reisser, J., 2017. River plastic emissions to the world's oceans. Nature Communications 8, 15611. https://doi.org/10.1038/ncomms 15611

Lee, H., Shim, W.J., Kwon, J.-H., 2014. Sorption capacity of plastic debris for hydrophobic organic chemicals. Sci. Total Environ. 470-471, 1545-1552. https://doi.org/10.1016/j.scitotenv.2013.08.023

Lee, Y.K., Romera-Castillo, C., Hong, S., Hur, J., 2020. Characteristics of microplastic polymer-derived dissolved organic matter and its potential as a disinfection byproduct precursor. Water Res. 175, 115678. https://doi.org/10.1016/j.watres.2020.115678

Lemaire, J., Arnaud, R., Gardette, J.L., Ginhac, J.M., Li, T., Fanton, E., 1979. Vieillissement des polymères : empirisme ou science?. Caoutchoucs et Plastiques 593. 
Lemaire, J., Gardette, J.-L., Lacoste, J., Delprat, P., Vaillant, D., 1996. Mechanisms of Photooxidation of Polyolefins: Prediction of Lifetime in Weathering Conditions, in: Clough, R.L., Billingham, N.C., Gillen, K.T. (Eds.), Polymer Durability, Advances in Chemistry. American Chemical Society, Washington, DC, pp. 577-598. https://doi.org/10.1021/ba-1996-0249.ch035

Lenz, R., Enders, K., Stedmon, C.A., Mackenzie, D.M.A., Nielsen, T.G., 2015. A critical assessment of visual identification of marine microplastic using Raman spectroscopy for analysis improvement. Mar. Pollut. Bull. 100, 82-91. https://doi.org/10.1016/j.marpolbul.2015.09.026

León, V.M., García, I., González, E., Samper, R., Fernández-González, V., Muniategui-Lorenzo, S., 2018. Potential transfer of organic pollutants from littoral plastics debris to the marine environment. Environ. Pollut. 236, 442-453. https://doi.org/10.1016/j.envpol.2018.01.114

Li, J., Zhang, K., Zhang, H., 2018. Adsorption of antibiotics on microplastics. Environ. Pollut. 237, 460-467. https://doi.org/10.1016/j.envpol.2018.02.050

Liu, G., Zhu, Z., Yang, Y., Sun, Y., Yu, F., Ma, J., 2019. Sorption behavior and mechanism of hydrophilic organic chemicals to virgin and aged microplastics in freshwater and seawater. Environ. Pollut. 246, $26-33$. https://doi.org/10.1016/j.envpol.2018.11.100

Liu, P., Lu, K., Li, J., Wu, X., Qian, L., Wang, M., Gao, S., 2020a. Effect of aging on adsorption behavior of polystyrene microplastics for pharmaceuticals: Adsorption mechanism and role of aging intermediates. Journal of Hazardous Materials 384, 121193. https://doi.org/10.1016/j.jhazmat.2019.121193

Liu, P., Zhan, X., Wu, X., Li, J., Wang, H., Gao, S., 2020b. Effect of weathering on environmental behavior of microplastics: Properties, sorption and potential risks. Chemosphere 242, 125193. https://doi.org/10.1016/j.chemosphere.2019.125193

Llorca, M., Farré, M., Karapanagioti, H.K., Barceló, D., 2014. Levels and fate of perfluoroalkyl substances in beached plastic pellets and sediments collected from Greece. Mar. Pollut. Bull. 87, 286-291. https://doi.org/10.1016/j.marpolbul.2014.07.036

Lobo, H., Bonilla, J.V., 2003. Handbook of Plastics Analysis. CRC Press.

Luo, H., Li, Y., Zhao, Y., Xiang, Y., He, D., Pan, X., 2020. Effects of accelerated aging on characteristics, leaching, and toxicity of commercial lead chromate pigmented microplastics. Environ. Pollut. 257, 113475. https://doi.org/10.1016/j.envpol.2019.113475

Lv, Y., Huang, Y., Yang, J., Kong, M., Yang, H., Zhao, J., Li, G., 2015. Outdoor and accelerated laboratory weathering of polypropylene: A comparison and correlation study. Polym. Degrad. Stab. 112, 145-159. https://doi.org/10.1016/j.polymdegradstab.2014.12.023

Mai, L., Bao, L.-J., Shi, L., Liu, L.-Y., Zeng, E.Y., 2018. Polycyclic aromatic hydrocarbons affiliated with microplastics in surface waters of Bohai and Huanghai Seas, China. Environ. Pollut. 241, 834-840. https://doi.org/10.1016/j.envpol.2018.06.012

Malajati, Y., 2009. Etude des mécanismes de photovieillissement de revêtements organiques anti-corrosion pour application comme peintures marines. Influence de l'eau. Blaise Pascal University.

Malajati, Y., Therias, S., Gardette, J.-L., 2011. Influence of water on the photooxidation of KHJ® phenoxy resins, 1. Mechanisms. Polym. Degrad. Stab. 96, 144-150. https://doi.org/10.1016/j.polymdegradstab.2010.10.007

Massey, S., Adnot, A., Rjeb, A., Roy, D., 2007. Action of water in the degradation of low-density polyethylene studied by X-ray photoelectron spectroscopy. Express Polymer Letters 1, 506-511. https://doi.org/10.3144/expresspolymlett.2007.72

Mato, Y., Isobe, T., Takada, H., Kanehiro, H., Ohtake, C., Kaminuma, T., 2001. Plastic Resin Pellets as a Transport Medium for Toxic Chemicals in the Marine Environment. Environ. Sci. Technol. 35, 318-324. https://doi.org/10.1021/es0010498

Maxwell, A., Broughton, W., Dean, G., 2005. Review of accelerated ageing methods and lifetime prediction techniques for polymeric materials.

Mecozzi, M., Pietroletti, M., Monakhova, Y.B., 2016. FTIR spectroscopy supported by statistical techniques for the structural characterization of plastic debris in the marine environment: Application to monitoring studies. Mar. Pollut. Bull. 106, 155-161. https://doi.org/10.1016/j.marpolbul.2016.03.012

Mizukawa, K., Takada, H., Ito, M., Geok, Y.B., Hosoda, J., Yamashita, R., Saha, M., Suzuki, S., Miguez, C., Frias, J., Antunes, J.C., Sobral, P., Santos, I., Micaelo, C., Ferreira, A.M., 2013. Monitoring of a wide range of organic micropollutants on the Portuguese coast using plastic resin pellets. Mar. Pollut. Bull. 70, 296302. https://doi.org/10.1016/j.marpolbul.2013.02.008

Moore, C.J., 2008. Synthetic polymers in the marine environment: A rapidly increasing, long-term threat. Environ. Res. 108, 131-139. https://doi.org/10.1016/j.envres.2008.07.025

Müller, A., Becker, R., Dorgerloh, U., Simon, F.-G., Braun, U., 2018. The effect of polymer aging on the uptake of fuel aromatics and ethers by microplastics. Environ. Pollut. 240, 639-646. https://doi.org/10.1016/j.envpol.2018.04.127 
Nagai, N., Okumura, H., Imai, T., Nishiyama, I., 2003. Depth profile analysis of the photochemical degradation of polycarbonate by infrared spectroscopy. Polymer Degradation and Stability 81, 491-496. https://doi.org/10.1016/S0141-3910(03)00135-6

Nakashima, E., Isobe, A., Kako, S., Itai, T., Takahashi, S., Guo, X., 2016. The potential of oceanic transport and onshore leaching of additive-derived lead by marine macro-plastic debris. Mar. Pollut. Bull. 107, 333 339. https://doi.org/10.1016/j.marpolbul.2016.03.038

Norrish, R.G.W., Bamford, C.H., 1936. Photodecomposition of Aldehydes and Ketones. Nature 138, 1016-1016. https://doi.org/10.1038/1381016a0

O'Brine, T., Thompson, R.C., 2010. Degradation of plastic carrier bags in the marine environment. Mar. Pollut. Bull. 60, 2279-2283. https://doi.org/10.1016/j.marpolbul.2010.08.005

O’Connor, I.A., Golsteijn, L., Hendriks, A.J., 2016. Review of the partitioning of chemicals into different plastics: Consequences for the risk assessment of marine plastic debris. Mar. Pollut. Bull. 113, 17-24. https://doi.org/10.1016/j.marpolbul.2016.07.021

Ogata, Y., Takada, H., Mizukawa, K., Hirai, H., Iwasa, S., Endo, S., Mato, Y., Saha, M., Okuda, K., Nakashima, A., Murakami, M., Zurcher, N., Booyatumanondo, R., Zakaria, M.P., Dung, L.Q., Gordon, M., Miguez, C., Suzuki, S., Moore, C., Karapanagioti, H.K., Weerts, S., McClurg, T., Burres, E., Smith, W., Velkenburg, M.V., Lang, J.S., Lang, R.C., Laursen, D., Danner, B., Stewardson, N., Thompson, R.C., 2009. International Pellet Watch: Global monitoring of persistent organic pollutants (POPs) in coastal waters. 1. Initial phase data on PCBs, DDTs, and HCHs. Mar. Pollut. Bull. 58, 1437-1446. https://doi.org/10.1016/j.marpolbul.2009.06.014

Pavia, D.L., Lampman, G.M., Kriz, G.S., Vyvyan, J.A., 2008. Introduction to Spectroscopy. Cengage Learning.

Pegram, J.E., Andrady, A.L., 1989. Outdoor weathering of selected polymeric materials under marine exposure conditions. Polym. Degrad. Stab. 26, 333-345. https://doi.org/10.1016/0141-3910(89)90112-2

Peng, L., Fu, D., Qi, H., Lan, C.Q., Yu, H., Ge, C., 2020. Micro- and nano-plastics in marine environment: Source, distribution and threats - A review. Sci. Total Environ. 698, 134254. https://doi.org/10.1016/j.scitotenv.2019.134254

Philip, M., Al-Azzawi, F., 2018. Effects of Natural and Artificial Weathering on the Physical Properties of Recycled Poly(ethylene terephthalate). J Polym Environ 26, 3139-3148. https://doi.org/10.1007/s10924018-1191-x

Pickett, J.E., Gibson, D.A., Gardner, M.M., 2008. Effects of irradiation conditions on the weathering of engineering thermoplastics. Polymer Degradation and Stability 93, 1597-1606. https://doi.org/10.1016/j.polymdegradstab.2008.02.009

Pimentel, L.R., Gardette, J.-L., 2001. Ageing and characterisation of PVC-based compounds utilised for exterior applications in the building construction field 2: Artificial accelerated ageing with xenon light. Polymer Testing 6 .

Pimentel, L.R., Gardette, J.-L., Pereira Rocha, A., 2005. Artificial simulated and natural weathering of poly(vinyl chloride) for outdoor applications: the influence of water in the changes of properties. Polym. Degrad. Stab. 88, 357-362. https://doi.org/10.1016/j.polymdegradstab.2004.11.012

Plastics Europe, 2020. Plastics - the Facts 2020.

Plastics Europe, 2019a. Plastics - the Facts 2019.

Plastics Europe, 2019b. The Circular Economy for Plastics - A European Overview.

Pospíśil, J., Pilař, J., Billingham, N.C., Marek, A., Horák, Z., Nešpůrek, S., 2006. Factors affecting accelerated testing of polymer photostability. Polym. Degrad. Stab. 91, 417-422. https://doi.org/10.1016/j.polymdegradstab.2005.01.049

Pozo, K., Urbina, W., Gómez, V., Torres, M., Nuñez, D., Přibylová, P., Audy, O., Clarke, B., Arias, A., Tombesi, N., Guida, Y., Klánová, J., 2020. Persistent organic pollutants sorbed in plastic resin pellet — "Nurdles" from coastal areas of Central Chile. Mar. Pollut. Bull. 151, 110786. https://doi.org/10.1016/j.marpolbul.2019.110786

Rabek, Jan.F., 1995. Polymer Photodegradation: Mechanisms and experimental methods. Springer Netherlands, Dordrecht.

Rabello, M.S., White, J.R., 1997. Crystallization and melting behaviour of photodegraded polypropylene - I. Chemi-crystallization. Polymer 38, 6379-6387. https://doi.org/10.1016/S0032-3861(97)00213-9

Rånby, B., 1989. Photodegradation and photo-oxidation of synthetic polymers. Journal of Analytical and Applied Pyrolysis 15, 237-247. https://doi.org/10.1016/0165-2370(89)85037-5

Ranjan, V.P., Goel, S., 2019. Degradation of Low-Density Polyethylene Film Exposed to UV Radiation in Four Environments. J. Hazard. Toxic Radioact. Waste 23, 04019015. https://doi.org/10.1061/(ASCE)HZ.2153-5515.0000453

Razanajatovo, R.M., Ding, J., Zhang, S., Jiang, H., Zou, H., 2018. Sorption and desorption of selected pharmaceuticals by polyethylene microplastics. Mar. Pollut. Bull. 136, 516-523. https://doi.org/10.1016/j.marpolbul.2018.09.048 
1053

11054

21055

31056

41057

51058

61059

71060

81061

91062

101063

111064

121065

131066

141067

151068

161069

171070

181071

191072

201073

211074

221075

231076

241077

251078

261079

271080

281081

291082

301083

311084

321085

331086

341087

351088

361089

371090

381091

391092

401093

411094

421095

431096

441097

451098

461099

471100

481101

491102

501102

511104

521104

531106

541107

551107

$\begin{array}{ll}56 & 1108 \\ 57 & 1109\end{array}$

571110

591111

601112

Resmeriță, A.-M., Coroaba, A., Darie, R., Doroftei, F., Spiridon, I., Simionescu, B.C., Navard, P., 2018. Erosion as a possible mechanism for the decrease of size of plastic pieces floating in oceans. Mar. Pollut. Bull. 127, 387-395. https://doi.org/10.1016/j.marpolbul.2017.12.025

Ribeiro-Claro, P., Nolasco, M.M., Araújo, C., 2017. Characterization of Microplastics by Raman Spectroscopy, in: Comprehensive Analytical Chemistry. Elsevier, pp. 119-151. https://doi.org/10.1016/bs.coac.2016.10.001

Rios, L.M., Jones, P.R., Moore, C., Narayan, U.V., 2010. Quantitation of persistent organic pollutants adsorbed on plastic debris from the Northern Pacific Gyre's “eastern garbage patch.” J. Environ. Mpnitoring 12 , 2226. https://doi.org/10.1039/c0em00239a

Rios, L.M., Moore, C., Jones, P.R., 2007. Persistent organic pollutants carried by synthetic polymers in the ocean environment. Mar. Pollut. Bull. 54, 1230-1237. https://doi.org/10.1016/j.marpolbul.2007.03.022

Rivaton, A., Gardette, J.-L., Mailhot, B., Morlat-Therlas, S., 2005. Basic Aspects of Polymer Degradation. Macromol. Symp. 225, 129-146. https://doi.org/10.1002/masy.200550711

Rochman, C.M., Kurobe, T., Flores, I., Teh, S.J., 2014. Early warning signs of endocrine disruption in adult fish from the ingestion of polyethylene with and without sorbed chemical pollutants from the marine environment. Sci. Total Environ. 493, 656-661. https://doi.org/10.1016/j.scitotenv.2014.06.051

Rosa, D.S., Angelini, J.M.G., Agnelli, J.A.M., Mei, L.H.I., 2005. The use of optical microscopy to follow the degradation of isotactic polypropylene (iPP) subjected to natural and accelerated ageing. Polymer Testing 24, 1022-1026. https://doi.org/10.1016/j.polymertesting.2005.07.009

Rouillon, C., Bussiere, P.-O., Desnoux, E., Collin, S., Vial, C., Therias, S., Gardette, J.-L., 2016. Is carbonyl index a quantitative probe to monitor polypropylene photodegradation? Polym. Degrad. Stab. 128, 200-208. https://doi.org/10.1016/j.polymdegradstab.2015.12.011

Rowenczyk, L., Dazzi, A., Deniset-Besseau, A., Beltran, V., Goudounèche, D., Wong-Wah-Chung, P., Boyron, O., George, M., Fabre, P., Roux, C., Mingotaud, A.F., Halle, A. ter, 2020. Microstructure Characterization of Oceanic Polyethylene Debris. Environ. Sci. Technol. 54, 4102-4109. https://doi.org/10.1021/acs.est.9b07061

Rugg, F.M., Smith, J.J., Bacon, R.C., 1954. Infrared spectrophotometric studies on polyethylene. II. Oxidation. Journal of Polymer Science 13, 535-547. https://doi.org/10.1002/pol.1954.120137202

Rummel, C.D., Jahnke, A., Gorokhova, E., Kühnel, D., Schmitt-Jansen, M., 2017. Impacts of Biofilm Formation on the Fate and Potential Effects of Microplastic in the Aquatic Environment. Environ. Sci. Technol. Lett. 4, 258-267. https://doi.org/10.1021/acs.estlett.7b00164

Sadri, S.S., Thompson, R.C., 2014. On the quantity and composition of floating plastic debris entering and leaving the Tamar Estuary, Southwest England. Mar. Pollut. Bull. 81, 55-60. https://doi.org/10.1016/j.marpolbul.2014.02.020

Schmidt, C., Krauth, T., Wagner, S., 2017. Export of Plastic Debris by Rivers into the Sea. Environ. Sci. Technol. 51, 12246-12253. https://doi.org/10.1021/acs.est.7b02368

Scircle, A., Cizdziel, J.V., Tisinger, L., Anumol, T., Robey, D., 2020. Occurrence of Microplastic Pollution at Oyster Reefs and Other Coastal Sites in the Mississippi Sound, USA: Impacts of Freshwater Inflows from Flooding. Toxics 8, 35. https://doi.org/10.3390/toxics8020035

Scoponi, M., Cimmino, S., Kaci, M., 2000. Photo-stabilisation mechanism under natural weathering and accelerated photo-oxidative conditions of LDPE ®1ms for agricultural applications. Polymer 41, 79697980.

Shen, X.-C., Li, D.-C., Sima, X.-F., Cheng, H.-Y., Jiang, H., 2018. The effects of environmental conditions on the enrichment of antibiotics on microplastics in simulated natural water column. Environ. Res. 166, 377383. https://doi.org/10.1016/j.envres.2018.06.034

Shyichuk, A., Melnyk, D., White, J.R., 2003. Delocalized free electron densities in degraded polystyrene and polypropylene macroradicals: The source of different photooxidation rates. Journal of Polymer Science Part A: Polymer Chemistry 41, 1070-1076. https://doi.org/10.1002/pola.10645

Shyichuk, A.V., White, J.R., Craig, I.H., Syrotynska, I.D., 2005. Comparison of UV-degradation depth-profiles in polyethylene, polypropylene and an ethylene-propylene copolymer. Polym. Degrad. Stab. 88, 415-419. https://doi.org/10.1016/j.polymdegradstab.2004.12.006

Silva, A.B., Bastos, A.S., Justino, C.I.L., da Costa, J.P., Duarte, A.C., Rocha-Santos, T.A.P., 2018. Microplastics in the environment: Challenges in analytical chemistry - A review. Anal. Chim. Acta. 1017, 1-19. https://doi.org/10.1016/j.aca.2018.02.043

Singh, B., Sharma, N., 2008. Mechanistic implications of plastic degradation. Polym. Degrad. Stab. 93, 561-584. https://doi.org/10.1016/j.polymdegradstab.2007.11.008

Sinturel, C., Philippart, J.-L., Lemaire, J., Gardette, L., 1999. Photooxidation of ®re retarded polypropylene. I. Photoageing in accelerated conditions. European Polymer Journal 9.

Skoog, D.A., Crouch, S.R., Holler, F.J., 2007. Principles of instrumental analysis. Thomson Brooks/Cole, Belmont, CA. 
Sobhani, Z., Zhang, X., Gibson, C., Naidu, R., Megharaj, M., Fang, C., 2020. Identification and visualisation of microplastics/nanoplastics by Raman imaging (i): Down to $100 \mathrm{~nm}$. Water Res. 174, 115658. https://doi.org/10.1016/j.watres.2020.115658

Song, Y.K., Hong, S.H., Jang, M., Han, G.M., Jung, S.W., Shim, W.J., 2017. Combined Effects of UV Exposure Duration and Mechanical Abrasion on Microplastic Fragmentation by Polymer Type. Environ. Sci. Technol. 51, 4368-4376. https://doi.org/10.1021/acs.est.6b06155

Suhrhoff, T.J., Scholz-Böttcher, B.M., 2016. Qualitative impact of salinity, UV radiation and turbulence on leaching of organic plastic additives from four common plastics — A lab experiment. Mar. Pollut. Bull. 102, 84-94. https://doi.org/10.1016/j.marpolbul.2015.11.054

Syakti, A.D., Bouhroum, R., Hidayati, N.V., Koenawan, C.J., Boulkamh, A., Sulistyo, I., Lebarillier, S., Akhlus, S., Doumenq, P., Wong-Wah-Chung, P., 2017. Beach macro-litter monitoring and floating microplastic in a coastal area of Indonesia. Mar. Pollut. Bull. 122, 217-225. https://doi.org/10.1016/j.marpolbul.2017.06.046

Syakti, A.D., Hidayati, N.V., Jaya, Y.V., Siregar, S.H., Yude, R., Suhendy, Asia, L., Wong-Wah-Chung, P., Doumenq, P., 2018. Simultaneous grading of microplastic size sampling in the Small Islands of Bintan water, Indonesia. Mar. Pollut. Bull. 137, 593-600. https://doi.org/10.1016/j.marpolbul.2018.11.005

Taghavi, N., Singhal, N., Zhuang, W.-Q., Baroutian, S., 2021. Degradation of plastic waste using stimulated and naturally occurring microbial strains. Chemosphere $263, \quad 127975$. https://doi.org/10.1016/j.chemosphere.2020.127975

Tang, C.-C., Chen, H.-I., Brimblecombe, P., Lee, C.-L., 2019. Morphology and chemical properties of polypropylene pellets degraded in simulated terrestrial and marine environments. Mar. Pollut. Bull. 149, 110626. https://doi.org/10.1016/j.marpolbul.2019.110626

Tang, C.-C., Chen, H.-I., Brimblecombe, P., Lee, C.-L., 2018. Textural, surface and chemical properties of polyvinyl chloride particles degraded in a simulated environment. Mar. Pollut. Bull. 133, 392-401. https://doi.org/10.1016/j.marpolbul.2018.05.062

Taniguchi, S., Colabuono, F.I., Dias, P.S., Oliveira, R., Fisner, M., Turra, A., Izar, G.M., Abessa, D.M.S., Saha, M., Hosoda, J., Yamashita, R., Takada, H., Lourenço, R.A., Magalhães, C.A., Bícego, M.C., Montone, R.C., 2016. Spatial variability in persistent organic pollutants and polycyclic aromatic hydrocarbons found in beach-stranded pellets along the coast of the state of São Paulo, southeastern Brazil. Mar. Pollut. Bull. 106, 87-94. https://doi.org/10.1016/j.marpolbul.2016.03.024

ter Halle, A., Ladirat, L., Gendre, X., Goudouneche, D., Pusineri, C., Routaboul, C., Tenailleau, C., Duployer, B., Perez, E., 2016. Understanding the Fragmentation Pattern of Marine Plastic Debris. Environ. Sci. Technol. 50, 5668-5675. https://doi.org/10.1021/acs.est.6b00594

ter Halle, A., Ladirat, L., Martignac, M., Mingotaud, A.F., Boyron, O., Perez, E., 2017. To what extent are microplastics from the open ocean weathered? Environ. Pollut. 227, 167-174. https://doi.org/10.1016/j.envpol.2017.04.051

Teuten, E.L., Rowland, S.J., Galloway, T.S., Thompson, R.C., 2007. Potential for Plastics to Transport Hydrophobic Contaminants. Environ. Sci. Technol. 41, 7759-7764. https://doi.org/10.1021/es071737s

Teuten, E.L., Saquing, J.M., Knappe, D.R.U., Barlaz, M.A., Jonsson, S., Bjorn, A., Rowland, S.J., Thompson, R.C., Galloway, T.S., Yamashita, R., Ochi, D., Watanuki, Y., Moore, C., Viet, P.H., Tana, T.S., Prudente, M., Boonyatumanond, R., Zakaria, M.P., Akkhavong, K., Ogata, Y., Hirai, H., Iwasa, S., Mizukawa, K., Hagino, Y., Imamura, A., Saha, M., Takada, H., 2009. Transport and release of chemicals from plastics to the environment and to wildlife. Phil. Trans. R. Soc. B 364, 2027-2045. https://doi.org/10.1098/rstb.2008.0284

Therias, S., Rapp, G., Masson, C., Gardette, J.-L., 2021. Limits of UV-light acceleration on the photooxidation of $\begin{array}{llllll}\text { low-density polyethylene. } & \text { Polym. } & \text { Degrad. } & \text { Stab. } & 183, & 109443 .\end{array}$ https://doi.org/10.1016/j.polymdegradstab.2020.109443

Thermo Fisher Scientific, 2018. Guide to the identification of microplastics by FTIR and Raman spectroscopy (No. WHITE PAPER WP53077). ThermoScientific.

Tian, L., Chen, Q., Jiang, W., Wang, L., Xie, H., Kalogerakis, N., Ma, Y., Ji, R., 2019. A carbon-14 radiotracerbased study on the phototransformation of polystyrene nanoplastics in water versus in air. Environ. Sci.: Nano 6, 2907-2917. https://doi.org/10.1039/C9EN00662A

Tidjani, A., 2000. Comparison of formation of oxidation products during photo-oxidation of linear low density polyethylene under different natural and accelerated weathering conditions. Polym. Degrad. Stab. 68, 465-469.

Tidjani, A., 1996. Photooxidation of polypropylene under natural and accelerated weathering conditions 7.

Tiwari, M., Rathod, T.D., Ajmal, P.Y., Bhangare, R.C., Sahu, S.K., 2019. Distribution and characterization of microplastics in beach sand from three different Indian coastal environments. Mar. Pollut. Bull. 140, 262273. https://doi.org/10.1016/j.marpolbul.2019.01.055 
Torikai, A., Takeuchi, A., Nagaya, S., Fueki, K., 1986. Photodegradation of polyethylene: Effect of crosslinking on the oxygenated products and mechanical properties. Polymer Photochemistry 7, 199-211. https://doi.org/10.1016/0144-2880(86)90027-8

Tuasikal, M.A., Alothman, O.Y., Luqman, M., Al-Zahrani, S.M., Jawaid, M., 2014. Influence of Natural and Accelerated Weathering on the Mechanical Properties of Low-Density Polyethylene Films. International Journal of Polymer Analysis and Characterization 19, 189-203. https://doi.org/10.1080/1023666X.2014.877212

Turner, A., Arnold, R., Williams, T., 2020. Weathering and persistence of plastic in the marine environment: Lessons from LEGO. Environ. Pollut. 262, 114299. https://doi.org/10.1016/j.envpol.2020.114299

Van, A., Rochman, C.M., Flores, E.M., Hill, K.L., Vargas, E., Vargas, S.A., Hoh, E., 2012. Persistent organic pollutants in plastic marine debris found on beaches in San Diego, California. Chemosphere 86, 258-263. https://doi.org/10.1016/j.chemosphere.2011.09.039

Van der Vegt, A.K., 2002. From polymers to plastics. Delft University Press, The Netherlands.

van Sebille, E., Wilcox, C., Lebreton, L., Maximenko, N., Hardesty, B.D., van Franeker, J.A., Eriksen, M., Siegel, D., Galgani, F., Law, K.L., 2015. A global inventory of small floating plastic debris. Environ. Res. Lett. 10, 124006. https://doi.org/10.1088/1748-9326/10/12/124006

Verma, R., Vinoda, K.S., Papireddy, M., Gowda, A.N.S., 2016. Toxic Pollutants from Plastic Waste- A Review. Procedia Environmental Sciences 35, 701-708. https://doi.org/10.1016/j.proenv.2016.07.069

Vroom, R.J.E., Koelmans, A.A., Besseling, E., Halsband, C., 2017. Aging of microplastics promotes their ingestion by marine zooplankton. Environ. Pollut. 231, 987-996. https://doi.org/10.1016/j.envpol.2017.08.088

Wang, F., Shih, K.M., Li, X.Y., 2015. The partition behavior of perfluorooctanesulfonate (PFOS) and perfluorooctanesulfonamide (FOSA) on microplastics. Chemosphere 119, 841-847. https://doi.org/10.1016/j.chemosphere.2014.08.047

Wang, F., Wong, C.S., Chen, D., Lu, X., Wang, Fei, Zeng, E.Y., 2018. Interaction of toxic chemicals with microplastics: A critical review. Water Res. 139, 208-219. https://doi.org/10.1016/j.watres.2018.04.003

Wang, Z., Chen, M., Zhang, L., Wang, K., Yu, X., Zheng, Z., Zheng, R., 2018. Sorption behaviors of phenanthrene on the microplastics identified in a mariculture farm in Xiangshan Bay, southeastern China. Sci. Total Environ. 628-629, 1617-1626. https://doi.org/10.1016/j.scitotenv.2018.02.146

Wang, Z.-M., Wagner, J., Ghosal, S., Bedi, G., Wall, S., 2017. SEM/EDS and optical microscopy analyses of microplastics in ocean trawl and fish guts. Science of The Total Environment 603-604, 616-626. https://doi.org/10.1016/j.scitotenv.2017.06.047

Ward, C.P., Armstrong, C.J., Walsh, A.N., Jackson, J.H., Reddy, C.M., 2019. Sunlight Converts Polystyrene to Carbon Dioxide and Dissolved Organic Carbon. Environ. Sci. Technol. Lett. 6, 669-674. https://doi.org/10.1021/acs.estlett.9b00532

Watanabe, C., Tsuge, S., Ohtani, H., 2009. Development of new pyrolysis-GC/MS system incorporated with online micro-ultraviolet irradiation for rapid evaluation of photo, thermal, and oxidative degradation of polymers. Polym. Degrad. Stab. 94, 1467-1472. https://doi.org/10.1016/j.polymdegradstab.2009.05.005

Weinstein, J.E., Crocker, B.K., Gray, A.D., 2016. From macroplastic to microplastic: Degradation of high-density polyethylene, polypropylene, and polystyrene in a salt marsh habitat: Degradation of plastic in a salt marsh habitat. Environmental Toxicology and Chemistry 35, 1632-1640. https://doi.org/10.1002/etc.3432

Welden, N.A., Lusher, A., 2020. Microplastics, in: Plastic Waste and Recycling. Elsevier, pp. $223-249$. https://doi.org/10.1016/B978-0-12-817880-5.00009-8

White, C.C., Tan, K.T., Hunston, D.L., Nguyen, T., Benatti, D.J., Stanley, D., Chin, J.W., 2011. Laboratory accelerated and natural weathering of styrene-ethylene-butylene-styrene (SEBS) block copolymer. Polym. Degrad. Stab. 96, 1104-1110. https://doi.org/10.1016/j.polymdegradstab.2011.03.003

White, J.R., 2006. Polymer ageing: physics, chemistry or engineering? Time to reflect. Comptes Rendus Chimie 9, 1396-1408. https://doi.org/10.1016/j.crci.2006.07.008

White, J.R., Shyichuk, A.V., 2007. Effect of stabilizer on scission and crosslinking rate changes during photooxidation of polypropylene. Polym. Degrad. Stab. 92, 2095-2101. https://doi.org/10.1016/j.polymdegradstab.2007.07.013

Wright, S.L., Thompson, R.C., Galloway, T.S., 2013. The physical impacts of microplastics on marine organisms: A review. Environ. Pollut. 178, 483-492. https://doi.org/10.1016/j.envpol.2013.02.031

Wypych, J., 1990. Weathering Handbook., 1st ed. Chemtec, Toronto.

Yakimets, I., Lai, D., Guigon, M., 2004. Effect of photo-oxidation cracks on behaviour of thick polypropylene samples. Polym. Degrad. Stab. 86, 59-67. https://doi.org/10.1016/j.polymdegradstab.2004.01.013

Yang, X.F., Li, J., Croll, S.G., Tallman, D.E., Bierwagen, G.P., 2003. Degradation of low gloss polyurethane aircraft coatings under UV and prohesion alternating exposures. Polym. Degrad. Stab. 80, 51-58. https://doi.org/10.1016/S0141-3910(02)00382-8 
Yeo, B.G., Takada, H., Taylor, H., Ito, M., Hosoda, J., Allinson, M., Connell, S., Greaves, L., McGrath, J., 2015. POPs monitoring in Australia and New Zealand using plastic resin pellets, and International Pellet Watch as a tool for education and raising public awareness on plastic debris and POPs. Mar. Pollut. Bull. 101, 137-145. https://doi.org/10.1016/j.marpolbul.2015.11.006

Yu, Q., Hu, X., Yang, B., Zhang, G., Wang, J., Ling, W., 2020. Distribution, abundance and risks of microplastics in the environment. Chemosphere 249, 126059. https://doi.org/10.1016/j.chemosphere.2020.126059

Yuzawa, T., Watanabe, C., Nemoto, N., Ohtani, H., 2013. Rapid evaluation of photo, thermal and oxidative degradation of high impact polystyrene by a xenon lamp-based online ultraviolet irradiation-pyrolysis$\begin{array}{lllll}\text { GC/MS } & \text { system. } & \text { Polym. } & \text { Degrad. } & \text { Stab. }\end{array}$ https://doi.org/10.1016/j.polymdegradstab.2012.11.005

Zarfl, C., Matthies, M., 2010. Are marine plastic particles transport vectors for organic pollutants to the Arctic? Mar. Pollut. Bull. 60, 1810-1814. https://doi.org/10.1016/j.marpolbul.2010.05.026

Zettler, E.R., Mincer, T.J., Amaral-Zettler, L.A., 2013. Life in the "Plastisphere": Microbial Communities on Plastic Marine Debris. Environ. Sci. Technol. 47, 7137-7146. https://doi.org/10.1021/es401288x

Zhang, H., 2017. Transport of microplastics in coastal seas. Estuarine, Coastal and Shelf Science 199, 74-86. https://doi.org/10.1016/j.ecss.2017.09.032

Zhang, W., Ma, X., Zhang, Z., Wang, Y., Wang, Juying, Wang, Jing, Ma, D., 2015. Persistent organic pollutants carried on plastic resin pellets from two beaches in China. Mar. Pollut. Bull. 99, $28-34$. https://doi.org/10.1016/j.marpolbul.2015.08.002

Zhu, L., Zhao, S., Bittar, T.B., Stubbins, A., Li, D., 2020. Photochemical dissolution of buoyant microplastics to dissolved organic carbon: Rates and microbial impacts. Journal of Hazardous Materials 383, 121065. https://doi.org/10.1016/j.jhazmat.2019.121065

Zweifel, H., 1998. Stabilization of Polymeric Materials, Macromolecular Systems - Materials Approach. SpringerVerlag, Berlin Heidelberg. https://doi.org/10.1007/978-3-642-80305-5 


\section{Declaration of interests}

$\bigotimes$ The authors declare that they have no known competing financial interests or personal relationships that could have appeared to influence the work reported in this paper.

$\square$ The authors declare the following financial interests/personal relationships which may be considered as potential competing interests:

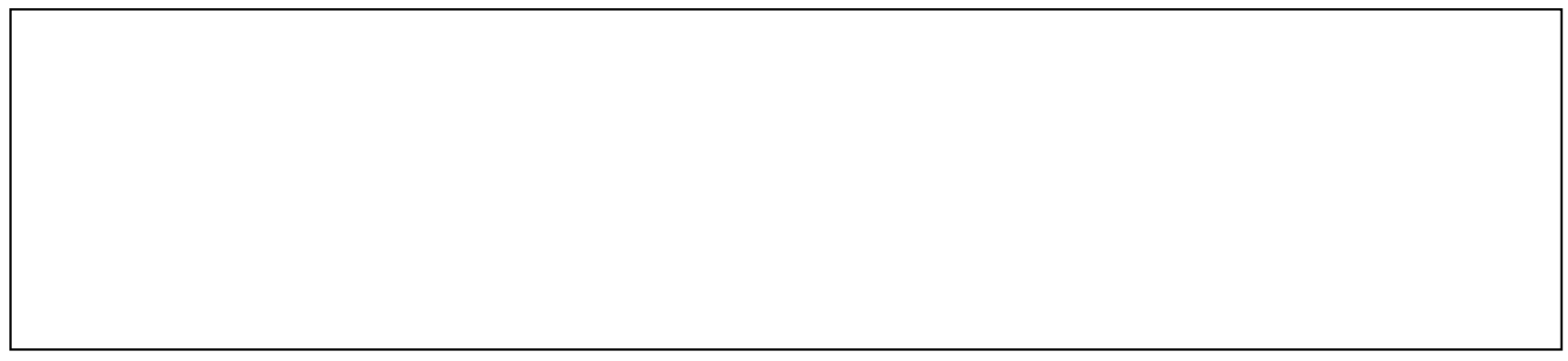

